\title{
New Approaches Toward the Hydrogen Production From Formic Acid Dehydrogenation Over Pd-Based Heterogeneous Catalysts
}

\author{
Miriam Navlani-García ${ }^{1 *}, K_{\text {Khsuke Mori }}^{1,2,3}$, David Salinas-Torres ${ }^{1}$, Yasutaka Kuwahara ${ }^{1,3}$ \\ and Hiromi Yamashita ${ }^{1,3}$ \\ 1 Division of Materials and Manufacturing Science, Graduate School of Engineering, Osaka University, 2-1 Yamada-oka, Suita, \\ Osaka, Japan, ${ }^{2}$ PRESTO, Japan Science and Technology Agency (JST), Kawaguchi, Japan, ${ }^{3}$ Unit of Elements Strategy \\ Initiative for Catalysts \& Batteries (ESICB), Kyoto University, Katsura, Kyoto, Japan
}

OPEN ACCESS

Edited by:

Ashok K. Sundramoorthy,

SRM Institute of Science and

Technology, India

Reviewed by:

Rajib Paul,

Case Western Reserve University,

United States

Yan Jiao,

University of Adelaide, Australia

Yang $L i$,

Tianjin University, China

*Correspondence:

Miriam Navlani-García

miriam@mat.eng.osaka-u.ac.jp;

miriam.navlani@ua.es

Specialty section:

This article was submitted to Carbon-Based Materials,

a section of the journal

Frontiers in Materials

Received: 28 November 2018 Accepted: 25 February 2019

Published: 22 March 2019

Citation:

Navlani-García M, Mori K Salinas-Torres D, Kuwahara $Y$ and Yamashita H (2019) New Approaches

Toward the Hydrogen Production From Formic Acid Dehydrogenation Over Pd-Based Heterogeneous

Catalysts. Front. Mater. 6:44.

doi: 10.3389/fmats.2019.00044
The urgency for finding clean energy sources is nowadays latent, and the role of hydrogen in the future of energy is well-recognized. However, there are still various barriers that limit the widespread utilization of hydrogen, which are mainly related to its storage and transportation. Chemical hydrogen storage stands out as a suitable alternative to traditional physical storage methods, and formic acid holds tremendous promise within the molecules studied so far. This review summarizes some of the recent approaches considered in our research group for the preparation of efficient catalysts for the production of hydrogen via dehydrogenation of formic acid by using Pd-based heterogeneous catalysts supported on carbon or carbon-containing materials. Several routes were considered to attain efficient catalysts, from the optimization of the size and composition of the nanoparticles to the modulation of important features of the support, such as the porous texture and nitrogen doping level.

Keywords: hydrogen generation, formic acid, carbon materials, palladium nanoparticles, chemical hydrogen storage

\section{INTRODUCTION}

Energy consumption is closely linked to the world's development, population and living standards. Currently, around $90 \%$ of the world's energy supply comes from fossil fuels, but their depletion, global energy consumption growth, and the $\mathrm{CO}_{2}$ emissions associated with their use are driving the search for alternative and sustainable energy sources. $\mathrm{CO}_{2}$ is a major greenhouse gas (along with water vapor), and its emission to the atmosphere is responsible for changing the natural greenhouse effect that makes the Earth habitable. The anthropogenic greenhouse effect is giving rise to catastrophic consequences, such as the increase in global temperatures, acidification of the oceans, melting arctic ice, decreased crop yield, human diseases and mortality, and so forth. Since $\mathrm{CO}_{2}$ generated by the energy sector accounts for about $65 \%$ of the total anthropogenic greenhouse gas emissions, it is evident that a massive change in the current energy scenario is necessary to avoid further irreversible environmental impacts (Durmaz, 2018). In this context, it was stated by the Intergovernmental Panel on Climate Change (IPCC) that the use of fossil fuels must be gradually reduced, and the utilization of renewable energy must rise to $80 \%$ of the power sector by 2050 to avoid catastrophic climate change. The importance of non-fossil fuels, such as solar, biofuel, wind, geothermal heat, etc., in palliating energy issues has been expressed in countless 
studies, but their widespread utilization is still limited because of their relatively high cost and technical difficulties in certai countries (Nguyen and Kakinaka, 2018).

The pivotal role of hydrogen in the future of energy is no longer questionable and, even though it is not naturally available as a ready-to-use molecule but is rather bound up in chemical compounds with other elements, its ideal status as an energy vector stems from its outstanding characteristics. The principal advantages of hydrogen as an energy carrier can be summarized as follows (Graetz, 2009; Rosen and Koohi-Fayegh, 2016):

- It can be manufactured from hydrocarbon and nonhydrocarbon energy sources.

- It can be utilized as a chemical fuel and as a chemical feedstock in a number of industrial processes and transportation.

- It is transportable.

- It is environmentally friendly. The combustion of hydrogen to produce energy $\left(\Delta \mathrm{H}=120 \mathrm{~kJ} \mathrm{~g}^{-1}\right)$ is, unlike the combustion of the commonly used fossil fuels (coal, oil, and natural gas), a $\mathrm{C}$-free reaction.

- In contrast to electricity, hydrogen can be stored in various forms that are usually classified as physical and chemical storage methods.

Nevertheless, safety issues related to its storage and transportation have limited its extensive utilization. However, despite the undesired properties of hydrogen in terms of safety, numerous studies revealed that the danger of hydrogen might not be worse than that shown by other fuels. Still, from a practical standpoint, storing, and transporting a hydrogen storage molecule that can provide hydrogen when required would be a better option than storing and transporting hydrogen in tanks for pressurized hydrogen gas or liquid hydrogen, which require high-pressure systems or high liquefaction energy.

Chemical hydrogen storage, in which hydridic/protonic $\mathrm{H}$ is combined with other elements, stands as a safe and more convenient option to the classical physical storage. The search for solid and liquid-state hydrogen storage materials has been the focus of fruitful investigations in the last decades. Examples of some representative hydrogen storage molecules include ammonia borane $\left(\mathrm{NH}_{3} \mathrm{BH}_{3}\right)$ (García-Aguilar et al., 2016a; Navlani-García et al., 2016a; Navlani-garcía et al., 2018), ammonia $\left(\mathrm{NH}_{3}\right)$ (Lan et al., 2012; Afif et al., 2016), methanol $\left(\mathrm{CH}_{3} \mathrm{OH}\right)$ (Nielsen et al., 2013; Monney et al., 2014), sodium borohydride $\left(\mathrm{NaBH}_{4}\right)$ (Chowdhury et al., 2015; Demirci, 2015), magnesium hydride $\left(\mathrm{MgH}_{2}\right)$ (Lillo-Ródenas et al., 2008; ElEskandarany et al., 2016) and formic acid (HCOOH) (NavlaniGarcía et al., 2015a; Mori et al., 2017b; Wu et al., 2017) with hydrogen contents of 19.5, 17.6, 12.6, 10.8, 7.6, and 4.4 wt.\% of hydrogen, respectively. However, the practical application of some of these hydrogen storage molecules is greatly limited due to their low kinetics for reversible $\mathrm{H}_{2}$ adsorption-desorption reactions, thermodynamic stability, low inherent thermal conductivity, high price, and toxicity (Czaun et al., 2014; Zhong et al., 2018).

Formic acid is currently considered one of the most promising candidates. It was identified as a potential hydrogen storage medium 40 years ago (Williams et al., 1978), but increasing interest in the development of catalysts to boost the hydrogen production from formic acid has mainly been generated in the last decade. Among the virtues of formic acid as hydrogen carrier, its high volume of $53 \mathrm{~g}_{\mathrm{H} 2} \mathrm{~L}^{-1}$ (higher than the 2020 target of $40 \mathrm{~g}_{\mathrm{H} 2} \mathrm{~L}^{-1}$ for on-board hydrogen storage for light-duty fuel cell vehicles updated by the U. S. Department of Energy (DOE) in May 2017), low-toxicity (median lethal dose, LD50 (oral, rat) value of $1,100 \mathrm{mg} \mathrm{kg}^{-1}$ ), non-flammability (flash point of $69^{\circ} \mathrm{C}$, much higher than that of methanol and gasoline (12 and $-40^{\circ} \mathrm{C}$, respectively) and biodegradability should be mentioned (Navlani-García et al., 2018a). Furthermore, it is in liquid phase at ambient temperature, which makes its transportation and refueling easy so that its handling could be comparable to that of diesel and gasoline (Enthaler et al., 2010).

It is well-known that formic acid decomposition can take place by dehydration (decarbonylation) and dehydrogenation (decarboxylation), which are represented by the following chemical equations (Eppinger and Huang, 2017):

Dehydration: $\mathrm{HCOOH} \leftrightarrow \mathrm{CO}+\mathrm{H}_{2} \mathrm{O} ;\left(\Delta \mathrm{G}^{\circ}=-12.4\right.$ $\mathrm{kJ} \cdot \mathrm{mol}^{-1}, \Delta \mathrm{H}^{\circ}=29.2 \mathrm{~kJ} \cdot \mathrm{mol}^{-1}$, and $\left.\Delta \mathrm{S}^{\circ}=139 \mathrm{~J} \cdot \mathrm{mol}^{-1} \cdot \mathrm{K}^{-1}\right)$

Dehydrogenation: $\mathrm{HCOOH} \leftrightarrow \mathrm{H}_{2}+\mathrm{CO}_{2} ;\left(\Delta \mathrm{G}^{\circ}=-32.9\right.$ $\mathrm{kJ} \cdot \mathrm{mol}^{-1}, \Delta \mathrm{H}^{\circ}=31.2 \mathrm{~kJ} \cdot \mathrm{mol}^{-1}$, and $\left.\Delta \mathrm{S}^{\circ}=216 \mathrm{~J} \cdot \mathrm{mol}^{-1} \cdot \mathrm{K}^{-1}\right)$

The gas mixture generated from the formic acid dehydrogenation reaction can be directly utilized as a feed gas for an $\mathrm{H}_{2}$ /air fuel cell (Loges et al., 2008) so that the dehydration route should be avoided to suppress the formation of $\mathrm{CO}$, which leads to the poisoning of the catalysts used in the fuel cell. Formic acid dehydration can be avoided through highly selective catalysts able to boost its dehydrogenation to generate $\mathrm{H}_{2}$ and $\mathrm{CO}_{2}$. It has been reported that the pathway followed in the decomposition of formic acid (by either dehydration or dehydrogenation) is strongly dependent on the catalytic surface, which controls the adsorption of formic acid molecules. It was claimed that large terrace sites tend to adsorb the molecules of formic acid following a bidentate form, which gives raise to the dehydrogenation pathway, while surface-unsaturated sites boost the dehydration pathway (Tedsree et al., 2011).

Besides its intrinsic features, another important aspect of the use of formic acid as a hydrogen storage material is that the $\mathrm{CO}_{2}$ generated in formic acid dehydrogenation can be subsequently hydrogenated so that formic acid molecules are regenerated in a carbon-free emission process (Fellay et al., 2008; Loges et al., 2008; Enthaler et al., 2010) that can be simply schematized in Figure 1.

Williams first reported on the electrochemical reduction of $\mathrm{CO}_{2}$ to formic acid in 1978 (Williams et al., 1978), and since then interesting investigations have been undertaken by using electrochemical (Lu et al., 2014; Gupta et al., 2016; Zhang et al., 2017b), photoelectrochemical (Lu et al., 2017; Jiang M. et al., 2018), catalytic (Moret et al., 2014; Mori et al., 2018), and photocatalytic (Premkumar and Ramaraj, 1997; Qin G. et al., 2013) approaches. However, despite the ideality of this system, several aspects should be considered to boost the thermodynamically uphill formation of liquid formic acid from gaseous $\mathrm{CO}_{2}$ and $\mathrm{H}_{2}$. Usually, the reaction of $\mathrm{CO}_{2}$ and $\mathrm{H}_{2}$ is 


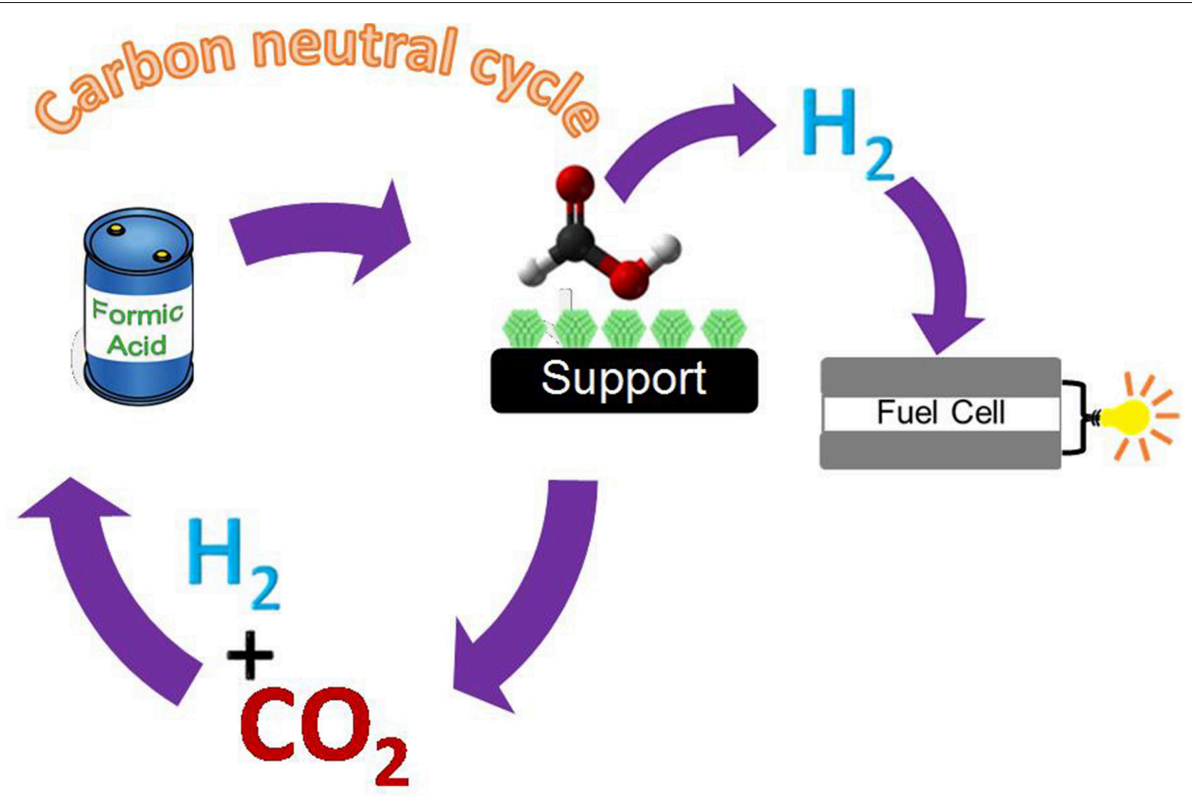

FIGURE 1 | Carbon-neutral energy storage using formic acid as a hydrogen carrier molecule.

through the water gas shift reaction, resulting in the formation of $\mathrm{CO}$ and $\mathrm{H}_{2} \mathrm{O}$ (Paul et al., 2015; Reddy and Smirniotis, 2015), but the selection of suitable experimental conditions (such as the use of inorganic or organic basis) and an appropriate catalyst might shift the reaction equilibria toward the hydrogenation of $\mathrm{CO}_{2}$ (Zhu and $\mathrm{Xu}, 2015$ ).

Since Coffey first reported the decomposition of formic acid over a homogeneous catalytic system in 1967 (Coffey, 1967), many investigations dealing with the preparation of highly active and robust homogeneous catalysts that selectively produce $\mathrm{H}_{2}$ and $\mathrm{CO}_{2}$ from formic acid under mild conditions have been documented (Fukuzumi et al., 2008, 2010; Mellmann et al., 2016), including ruthenium (Boddien et al., 2009; Czaun et al., 2014), rhodium (Strauss et al., 1979), iron (Boddien et al., 2010; Zell et al., 2013), and iridium (Bavykina et al., 2015; Czaun et al., 2016; Matsunami et al., 2017) complexes being some of the most representative studied catalysts. However, achieving competitive and selective heterogeneous catalysts under mild conditions is still a difficult task (Enthaler et al., 2010; Grasemann and Laurenczy, 2012).

The investigation of the decomposition of formic acid over heterogeneous catalysts dates back to the 1930s, but in the initial studies the optimization of the catalysts, as well as the measurement of the $\mathrm{CO}$ evolved from the formic acid dehydration side reaction, were not deeply considered (Grasemann and Laurenczy, 2012). In that case, the reaction has mainly been studied in the gas phase, and temperatures higher than $100^{\circ} \mathrm{C}$ (the normal boiling point of formic acid) or the use of an inert carrier gas to dilute formic acid below its saturated vapor pressure were needed, which, from the practical application viewpoint, would constitute additional complexity for the setup used to conduct the reaction test. Then, the development of heterogeneous catalysts for formic acid dehydrogenation in liquid-phase is highly desirable ( $\mathrm{Zhu}$ and $\mathrm{Xu}, 2015$ ). The search for an optimum heterogeneous catalyst encompasses the investigation of several active phases, mainly in the form of noble metal nanoparticles, but reports in which non-noble metal nanoparticles are studied can be also found in the literature, approaching this issue from both experimental and theoretical perspectives (Yoo et al., 2014).

Among all the catalysts studied in this application, those based on palladium have been claimed to be very promising alternatives, and they have received great attention not only because they are more tolerant to $\mathrm{CO}$ than other metals, but also because relatively high hydrogen conversion and selectivity values have been achieved under moderate temperatures ( $\mathrm{He}$ and $\mathrm{Li}, 2016)$. Thus, the research community interested in formic acid as a hydrogen carrier has devoted tremendous efforts to understand and optimize the Pd-based catalytic systems by enhancing either their performance under mild conditions or their stability and/or durability as well as selectivity. Some of the strategies tackled in this matter include the optimization of the active phase features (in terms of size, composition, structure, and so forth) as well as the impact of the support properties in modulating the final behavior of the catalysts by controlling the metal-support interaction or the acid/base properties. There are a number of supports investigated for this application, including silica (García-Aguilar et al., 2016b; Mori et al., 2017a), zeolites (Navlani-García et al., 2015a), metal-organic frameworks (MOFs) (Wen et al., 2017), etc. Among them, carbon materials are certainly the most extensively investigated so far. The virtues of carbon materials as catalytic support are nowadays recognized and they can be ascribed to unique properties that make them preferable over other common supports such as silica or 
TABLE 1 | Representative catalysts based on carbon materials used in the formic acid dehydrogenation reaction.

\begin{tabular}{|c|c|c|c|}
\hline Catalyst & $\mathrm{T}\left({ }^{\circ} \mathrm{C}\right)$ & TOF $\left(h^{-1}\right)$ & References \\
\hline $\mathrm{Pd} / \mathrm{C}$ & 25 & 64 & Wang Z.-L. et al., 2012 \\
\hline $\mathrm{Pd} / \mathrm{mpg}-\mathrm{C}_{3} \mathrm{~N}_{4}$ & 25 & 144 & Lee et al., 2014 \\
\hline $\mathrm{Pd} / \mathrm{C}$ & 25 & 304 & Jiang et al., 2014 \\
\hline $\mathrm{Pd} / \mathrm{CN}_{0.25}$ & 25 & 752 & Bi et al., 2016 \\
\hline $\mathrm{Pd} / \mathrm{C}$ & 25 & 835 & Li J. et al., 2017 \\
\hline $\mathrm{Pd} / \mathrm{NMC}-400$ & 25 & 913 & Sun et al., 2019 \\
\hline $\mathrm{Pd} / 1.0 \mathrm{Ti}-\mathrm{g}-\mathrm{C}_{3} \mathrm{~N}_{4}$ & 30 & 77 & Wu et al., 2017 \\
\hline $\mathrm{Pd} / \mathrm{C}$ & 30 & 228.3 & Wang X. et al., 2014 \\
\hline $\mathrm{Pd}_{\mid \mathrm{MP}} / \mathrm{CNF}-\mathrm{HHT}$ & 30 & 563.2 & Sanchez et al., 2018 \\
\hline Pd/carbon black & 30 & 1,815 & Zhang S. et al., 2017 \\
\hline $\mathrm{Pd} / \mathrm{N}-\mathrm{C}$ & 45 & 645 & Jeon et al., 2016 \\
\hline $\mathrm{Pd} / \mathrm{MSC}-30$ & 50 & 2623 & Zhu Q. L. et al., 2014 \\
\hline $\mathrm{Pd} / \mathrm{C}$ & 50 & 7,959 & Zhou et al., 2016 \\
\hline $\mathrm{Pd} / \mathrm{C}$ nanospheres & 60 & 7,256 & Zhu et al., 2015 \\
\hline $\mathrm{Pd} / \mathrm{N}-\mathrm{MSC}-30$ & 60 & 8,414 & Li Z. et al., 2017 \\
\hline $\mathrm{Ag} @ \mathrm{Pd} / \mathrm{C}(1: 1)$ & 20 & 192 & Tedsree et al., 2011 \\
\hline $\mathrm{Pd}_{1} \mathrm{Ag}_{6} / \mathrm{N}-\mathrm{rGO}$ & 25 & 171 & Huang et al., 2017 \\
\hline Ag@Pd/N-GCNT & 25 & 413 & Nabid et al., 2017 \\
\hline $\mathrm{PdAg} @ g-\mathrm{C}_{3} \mathrm{~N}_{4}$ & 25 & 420 & Liu et al., 2019 \\
\hline $\mathrm{Ag}_{74} \mathrm{Pd}_{26}$ /graphene & 25 & 572 & Yang et al., 2015 \\
\hline $\mathrm{AgPd} / \mathrm{C}$ & 30 & 854 & Feng et al., 2016 \\
\hline $\mathrm{C}-\mathrm{Ag}_{42} \mathrm{Pd}_{58}$ & 50 & 382 & Zhang et al., 2013 \\
\hline $\mathrm{Ag}_{9} \mathrm{Pd}{ }_{91} / \mathrm{g}-\mathrm{C}_{3} \mathrm{~N}_{4}$ & 50 & 480 & Yao et al., 2017 \\
\hline PdAg/amine-MSC & 75 & 5,638 & Masuda et al., 2018 \\
\hline $\mathrm{Au}_{6} \mathrm{Pd}_{4} /$ carbon black & 0 & 635 & Wu et al., 2014 \\
\hline $\mathrm{AuPd}-\mathrm{CeO}_{2} / \mathrm{N}-\mathrm{rGO}$ & 25 & 52.9 & Wang et al., 2014a \\
\hline $\mathrm{Au} @ \mathrm{Pd} / \mathrm{N}-\mathrm{mrGO}$ & 25 & 89.1 & Wang et al., 2013b \\
\hline $\mathrm{Pd}-\mathrm{Au}-\mathrm{Dy} / \mathrm{C}$ & 92 & 269 & Zhou et al., 2010 \\
\hline $\mathrm{Au}_{0.75} \mathrm{Pd}_{0.25} / \mathrm{C}-\mathrm{L}-7.5$ & 25 & 718 & Cheng et al., 2016 \\
\hline $\mathrm{Au}_{6} \mathrm{Pd}_{4}-\mathrm{L}-\mathrm{Mg}$ & 25 & 1,120 & Wu et al., 2015 \\
\hline $\mathrm{Co}_{1.6} \mathrm{Ag}_{62.2} \mathrm{Pd}_{36.2}$ /graphene & 25 & 110 & Yang et al., 2016 \\
\hline $\mathrm{Co}_{0.30} \mathrm{Au}_{0.35} \mathrm{Pd}_{0.35} / \mathrm{C}$ & 25 & 80 & Wang et al., 2013a \\
\hline
\end{tabular}

alumina (Rodríguez-Reinoso, 2010). Among those features, their resistance to basic and acid media, tailored porous structure, controllable hydrophilicity, and the possibility of incorporation of heteroatoms in their structure are of particular interest for the formic acid dehydrogenation reaction. Carbon materials are ideal catalytic support for the present application, not only because they serve as anchoring sites for the metal nanoparticles but also because they can be modified so as to incorporate basic functionalities that can be actively involved in the formic acid dehydrogenation reaction, ultimately resulting in highly performing catalysts.

In order to provide a wide view of the recent breakthroughs achieved by using catalysts based on carbon materials, some representative examples are listed in Table $\mathbf{1}$.

In this review, we address some of the recent studies conducted by our research group toward the design of Pd-based heterogeneous catalysts supported on carbon or carbon-containing materials for the formic acid dehydrogenation reaction in liquid phase.

\section{PD-BASED HETEROGENEOUS CATALYSTS SUPPORTED ON CARBON MATERIALS}

As it was previously mentioned, Pd-based catalysts have been claimed to be the most active toward hydrogen production from the formic acid dehydrogenation reaction. Numerous factors, such as morphology of the metallic active phase, composition and architecture of the nanoparticles, metal loading, etc., have already been investigated in an attempt to design efficient heterogeneous catalysts that can be competitive to those generally more active homogeneous systems, while offering the well-known advantages inherent to heterogeneous catalysis. Most of the investigated heterogeneous catalysts studied in this application are carbonsupported systems. Among them, activated carbon is the most extensively used support (Navlani-García et al., 2018a), which is due to its high surface area, which gives the possibility to achieve highly dispersed and well-distributed metal nanoparticles, which are accessible to the molecules involved in the reaction. However, interesting reports on several kinds of carbon materials and carbon-based materials, such as reduced graphene oxide (rGO) (Ping et al., 2013; Yan et al., 2018), graphene nanosheets (Qin Y.-L et al., 2013; Bulut et al., 2018) carbon nanospheres (Zhu et al., 2015; Zhang et al., 2017a), various nitrogen-doped carbon materials [carbon black (Jeon et al., 2016), carbon nanotubes (Podyacheva et al., 2018), carbon xerogels (Navlani-García et al., 2019), carbon nanosheets (Jiang Y. et al., 2018; Zhang et al., 2019)], mesoporous carbon (Masuda et al., 2018), hierarchical porous carbon (Lee et al., 2017), etc.), carbon-based composite supports (Qin et al., 2014), and also carbon-containing structures such as carbon nitride (Cai et al., 2013; Oh, 2016), can be found in the recent literature.

Herein some of the recent investigations performed in our research group will be summarized. The effect of the features of both metal active phase and carbon-based supports on the catalytic performance in the formic acid dehydrogenation reaction were studied in the investigations herein reviewed.

\section{Effect of the Nanoparticle Size}

The investigation of the active phase properties in the final catalytic performance is usually the cornerstone of the successful preparation of highly-performing catalysts. Active phases are usually in the form of metal nanoparticles, which tend to display higher catalytic reactivity by virtue of their small sizes and high surface-to-volume ratio and which, in turn, result in the presence of low-coordinated atoms (Xie and Schlücker, 2018). Numerous aspects such as nanoparticle size, shape, and electronic features have already been studied by those researchers tackling the design of catalysts for hydrogen production from the decomposition of formic acid.

Our research group was a pioneer in the investigation of the effect of the nanoparticle size in the decomposition of formic acid by assessing the activity of Pd-based catalysts (Navlani-García et al., 2015b, 2016b). In that study, the commercial activated carbon Shirasagi M (Osaka Gas Chemicals Co. Ltd.) was used as catalytic support. The synthesis of colloidal size-controlled Pd nanoparticles was based on a polyol process by using palladium (II) acetate as a Pd precursor, polyvinylpyrrolidone 
(PVP) as a stabilizing agent and ethylene glycol as the solvent and reducing agent. Several experimental parameters, such as $\mathrm{PVP} / \mathrm{Pd}$ molar ratio as well as synthesis temperature and time were used to tune the final size of the nanoparticles. The assynthetized colloidal nanoparticles were subsequently loaded on the carbon support and catalysts with an average nanoparticles size ranging from 2.7 to $5.5 \mathrm{~nm}(2.7,3.6,3.9,4.2$, and 5.5 for catalysts $\mathrm{Pd} / \mathrm{C}(1)-(5)$, respectively) were obtained. All catalysts were thoroughly characterized and the presence of $\mathrm{Pd}(0)$ in the nanoparticles was confirmed by X-ray photoelectron (XPS) and X-ray absorption fine structure (XAFS) spectroscopies. The hydrogen production was monitored by gas chromatography while the reaction took place at $30^{\circ} \mathrm{C}$. The results of the hydrogen produced after $3 \mathrm{~h}$ of reaction as a function of the size of the nanoparticles are summarized in Figure 2A. As can be observed in Figure 2A, sample $\mathrm{Pd} / \mathrm{C}(3)$, with an average nanoparticle size of $3.9 \mathrm{~nm}$ was the best-performing catalyst among those investigated. The volcano type relationship found between the hydrogen production ability and the size of the nanoparticles in that study was ascribed to the relative proportion of lowcoordinated atoms (LC) and high-coordinated atoms (HC) with respect to the total number of surface atoms present in the catalysts. To get further insight into the size-sensitivity observed, we assumed that Pd nanoparticles were cuboctahedral in shape, with a cubic close-packed structure in this size range and the full-shell nanoparticles model was adopted to calculate geometric parameters (Mori et al., 2004) (total surface atoms, LC and HC atoms). Turnover Frequency (TOF) values were calculated on the basis of these specific atoms (see Figure 2B). If all the atoms on the nanoparticle surface possess the same catalytic activity toward the hydrogen production, the TOF values calculated on the basis of the surface atoms should be the same regardless of the Pd particle sizes. As a result, TOF values changed by nearly $40 \%$ in the investigated size range and the values fell in the following order: $\mathrm{Pd} / \mathrm{C}(3)(3.9 \mathrm{~nm})>\mathrm{Pd} / \mathrm{C}(5)(5.5 \mathrm{~nm})$ $>\mathrm{Pd} / \mathrm{C}(2)(3.6 \mathrm{~nm})>\mathrm{Pd} / \mathrm{C}(4)(4.2 \mathrm{~nm})>\mathrm{Pd} / \mathrm{C}(1)(2.7 \mathrm{~nm})$. Such differences in the normalized TOF values indicated that all the Pd surface sites did not present the same catalytic activity in the formic acid decomposition. Furthermore, the tendencies observed for the TOF values calculated on the basis of LC and HC (see Figure 2B) suggested that the formic acid dehydrogenation reaction is "structure-sensitive" and the $\mathrm{HC} \mathrm{Pd}$ atoms at terrace sites act as the main active species.

Furthermore, a plausible mechanism pathway was proposed (Figure 3). According to that mechanism the following reaction steps would take place:-Step I: $\mathrm{O}-\mathrm{H}$ bond cleavage, providing a proton $\left(\mathrm{H}^{+}\right)$, and a palladium-formate $\left(\mathrm{Pd}-[\mathrm{HCOO}]^{-}\right)$ intermediate;-Step II: Pd-[HCOO $]^{-}$species undergo C-H bond dissociation, affording a palladium hydride $\left(\mathrm{Pd}-[\mathrm{H}]^{-}\right)$, and $\mathrm{CO}_{2}$;-Step III: the generation of $\mathrm{H}_{2}$ along with the regeneration of the $\mathrm{Pd}$ species take place after the recombination of $\mathrm{Pd}-[\mathrm{H}]^{-}$ with $\mathrm{a} \mathrm{H}^{+}$.

In addition, to get more information about the size sensitivity in the elementary steps of the formic acid dehydrogenation, Kinetic Isotope Effect (KIE) experiments were conducted by monitoring the evolution of the reaction using deuterated formic acid ( $\mathrm{HCOOD}$ and $\mathrm{DCOOH}$ ) and the results for each catalyst are listed in Table 2. As can be seen, the reaction rate constant ratio $\left(K_{H} / K_{D}\right)$ with $\mathrm{HCOOH}$ and $\mathrm{HCOOD}$ were similar for all the samples, suggesting that step I (O-H bond cleavage) was not dependent on the size of the NPs. The much larger $K_{H} / K_{D}$ values obtained with $\mathrm{HCOOH}$ and $\mathrm{DCOOH}$ for all the catalysts suggested that step II (C-H dissociation) was the ratedetermining reaction step. $K_{H} / K_{D}$ values were well-correlated with the catalytic tendency and the smallest values obtained with sample $\mathrm{Pd} / \mathrm{C}(3)$ confirmed the best performance displayed by that catalyst.

Subsequent studies also tackled the investigation of the size sensitivity. For instance, Zhang S. et al. (2017) also addressed the effect of Pd nanoparticles size in the formic acid decomposition over carbon-supported catalysts with average sizes ranging from 2.0 to $5.2 \mathrm{~nm}$ and using carbon black (Vulcan XC$72 \mathrm{R}$ ) as support. A capping-free synthetic protocol was then chosen, and the size of the nanoparticles was controlled by means of modifying the $\mathrm{pH}$ of the metal precursor, which was achieved with the addition of $\mathrm{Na}_{2} \mathrm{CO}_{3}, \mathrm{NH}_{3} \cdot \mathrm{H}_{2} \mathrm{O}$, or $\mathrm{NaOH}$. It was also observed that the catalytic performance displayed a volcano-type relationship with the Pd nanoparticle size, with the sample containing an average size of $2.2 \mathrm{~nm}$ being the most active among assessed. Following our study on the size-effect investigation (Navlani-García et al., 2016b), the volcano-type tendency observed in that case was also related to the proportion of low coordinated and high coordinated atoms in the nanoparticles. Such a volcano-type tendency for $\mathrm{Pd} / \mathrm{C}$ catalysts using activated carbon was also observed by Jeon and Chung (2017) by evaluating the activity of catalysts synthesized by several preparation methods [i.e., (i) adsorption of "ready-made" NPs; (ii) Pd precursor adsorption and reduction; (iii) adsorption of the Pd precursor plus deposition and reduction; (iv) Pd precursor ion exchange and reduction; (v) Pd precursor ion exchange, deposition and reduction; (vi) in situ metal sol formation and reduction; (vii) in situ metal sol formation, deposition and reduction]. Li and co-workers (Li J. et al., 2017) also reported on the effect of the Pd nanoparticles size for the formic acid dehydrogenation reaction by using carbon black (Vulcan XC-72R) as support. In that case, sodium citrate was used as a stabilizer and several Pd precursors to sodium citrate ratios were used so as to obtain Pd nanoparticles with average sizes ranging from 2.1 to $4.5 \mathrm{~nm}$. Under the experimental conditions used in that study, the smallest nanoparticles displayed the best performance among those investigated, which was related to a better dispersion of the nanoparticles and larger proportion of positively charged $\mathrm{Pd}$ species. Jin et al. also focused on the effect of the $\mathrm{Pd}$ nanoparticles size in their study on $\mathrm{Pd} / \mathrm{NH}_{2}-\mathrm{KIE}-6$ catalysts (being KIE-6a mesoporous silica) (Jin et al., 2018). The control of the nanoparticle size was achieved by means of modifying experimental conditions such as Pd precursor [i.e., palladium (II) nitrate hydrate, palladium (II) acetate, palladium (II) acetylacetonate, and potassium tetrachloropalladate (II)] and the stirring time used in the preparation of the catalysts and nanoparticles, with sizes ranging from 2.0 to $2.8 \mathrm{~nm}$ being measured by STEM analysis. In that case, the catalysts synthesized from palladium nitrate displayed the smallest NP size 

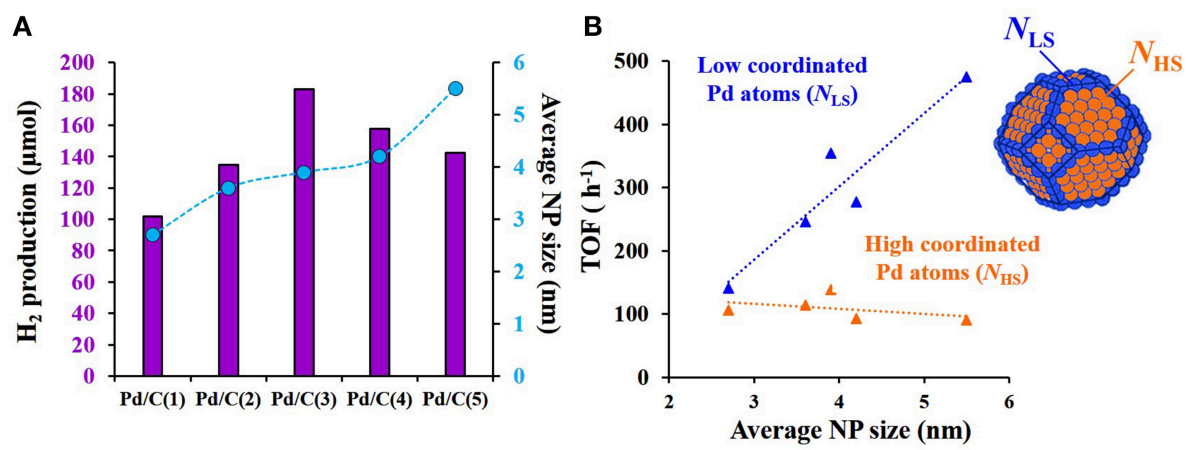

FIGURE 2 | (A) Relationship between $\mathrm{H}_{2}$ production after $3 \mathrm{~h}$ of reaction at $30^{\circ} \mathrm{C}$ and the average Pd nanoparticles (NP) size; (B) Normalized TOF values calculated on the basis of high-coordinated (HC) and low-coordinated (LC) as a function of the average Pd NP size. Adapted with permission from Navlani-García et al. (2016b). Copyright 2016 Wiley.

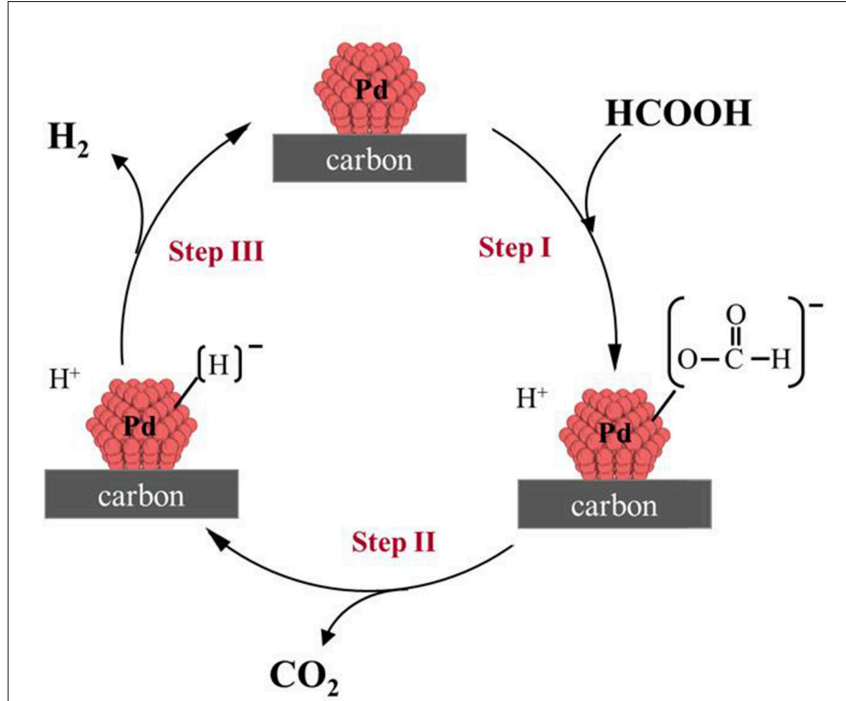

FIGURE 3 | Reaction mechanism proposed for $\mathrm{H}_{2}$ production from the formic acid dehydrogenation catalyzed by $\mathrm{Pd} / \mathrm{C}$ catalysts. and, in turn, showed the best performance in the formic acid dehydrogenation reaction.

\section{Effect of the Nanoparticle Composition}

As was previously mentioned, most of the heterogeneous catalysts used in the formic acid dehydrogenation reaction are based on Pd nanoparticles. However, Pd monometallic systems often suffer from deactivation caused by the adsorption of reaction intermediates on the surface of the nanoparticles. It was observed that the use of bimetallic or multimetallic systems can greatly palliate such problem and display better performance than the Pd monometallic counterpart. Such enhancement of the catalytic activity and selectivity of the bimetallic and multimetallic systems are usually ascribed to the modification of the Pd electronic density and geometric structure as well as resistance to poisoning intermediates (Zhang et al., 2017a).
TABLE 2 | KIE in the decomposition of formic acid.

\begin{tabular}{lcccc}
\hline Catalyst & $\begin{array}{c}\text { Average NP } \\
\text { size }(\mathbf{n m})^{\mathbf{a}}\end{array}$ & $\begin{array}{c}\text { Formic } \\
\text { acid }\end{array}$ & $\begin{array}{c}\text { Reaction rate } \\
\left(\boldsymbol{\mu} \mathbf{m o l} \cdot \mathbf{m i n}^{-1}\right)\end{array}$ & $\boldsymbol{k}_{\boldsymbol{H}} \mathbf{k}_{\boldsymbol{D}}$ \\
\hline $\mathrm{Pd} / \mathrm{C}(1)$ & $2.7 \pm 0.7$ & $\mathrm{HCOOH}$ & 0.64 & - \\
& & $\mathrm{HCOOD}$ & 0.20 & 3.13 \\
& & $\mathrm{HCOOH}$ & 0.02 & 35.20 \\
$\mathrm{Pd} / \mathrm{C}(2)$ & $3.6 \pm 0.8$ & $\mathrm{HCOOD}$ & 1.03 & - \\
& & $\mathrm{DCOOH}$ & 0.43 & 2.40 \\
& & $\mathrm{HCOOH}$ & 0.03 & 32.05 \\
$\mathrm{Pd} / \mathrm{C}(3)$ & $3.9 \pm 0.9$ & $\mathrm{HCOOD}$ & 0.78 & - \\
& & $\mathrm{DCOOH}$ & 0.17 & 2.29 \\
& & $\mathrm{HCOOH}$ & 1.80 & - \\
$\mathrm{Pd} / \mathrm{C}(4)$ & $4.2 \pm 0.6$ & $\mathrm{HCOOD}$ & 1.27 & 1.42 \\
& & $\mathrm{DCOOH}$ & 0.16 & 11.02 \\
& & $\mathrm{HCOOH}$ & 1.62 & - \\
$\mathrm{Pd} / \mathrm{C}(5)$ & $5.5 \pm 1.6$ & $\mathrm{HCOOD}$ & 0.34 & 4.76 \\
& & $\mathrm{DCOOH}$ & 0.12 & 13.85 \\
& & &
\end{tabular}

Adapted with permission from Navlani-García et al. (2016b). Copyright 2016 Wiley. a Average nanoparticle size determined by TEM analysis.

Furthermore, the utilization of bimetallic or multimetallic systems has been a widely employed strategy to reduce the cost of the final catalysts, particularly when non-noble metals are used in their compositions. A number of bimetallic and multimetallic heterogeneous catalysts, such as PdNi (Qin Y.-L et al., 2013), PdCu (Mori et al., 2015), PdAu (Huang et al., 2010; Gu et al., 2011; Wen et al., 2017) (Yan et al., 2015), PdAg (Mori et al., 2013; Wang et al., 2014b; Song et al., 2018), NiAuPd (Wang et al., 2014b; Bulut et al., 2018), PdCuCr (Mori et al., 2017b), AuAgPd (Li et al., 2015), CoAuPd (Wang et al., 2013a), etc., have already been reported to be active in the formic acid dehydrogenation reaction. Among them, noble metal-based systems have been so far the most studied, and PdAg-based catalysts have taken pole position in attracting extensive investigations (Mori et al., 2013; Masuda et al., 2018) as they have shown to be one of the most 
active catalysts in the formic acid decomposition reaction. Their superior performance is usually ascribed to the efficient charge transfer from $\mathrm{Ag}$ to $\mathrm{Pd}$ that results in electronically promoted Pd species, which are more active in catalyzing the formic acid dehydrogenation reaction. Since Tedsree et al. first reported on the potential of PdAg catalysts for this application in 2011 (Tedsree et al., 2011), an increasing number of studies on the decomposition of formic acid over PdAg catalysts can be found in the literature. Unlike monometallic catalysts, factors such as composition and configuration of the nanoparticles should be kept in mind while evaluating the performance of bimetallic or multimetallic catalysts. The complexity of these systems usually complicates the proper evaluation of only one aspect such as the composition or size of the bimetallic nanoparticles.

Our research group reported on the screening of carbonsupported PdAg catalysts prepared by loading pre-synthetized PVP-capped nanoparticles on activated carbon (Shirasagi $\mathrm{M})$, in which the composition of the nanoparticles was optimized in terms of $\mathrm{Pd} / \mathrm{Ag}$ and $\mathrm{PVP} /$ metal molar ratios (Navlani-García et al., 2016c).

As in the study of the effect of the size of monometallic Pd catalysts (Navlani-García et al., 2016b), the polyol method was utilized to synthesize colloidal nanoparticles. In this case, the composition of the nanoparticles was carefully controlled by modifying the initial amount of the metal precursors and capping agent (PVP) in the synthesis, so that 12 colloids with fixed $\mathrm{Pd}$ concentration, $\mathrm{PVP} /$ metal molar ratio of $1 / 1$, $5 / 1$ or $10 / 1$, and $\mathrm{Pd} / \mathrm{Ag}$ molar ratios of $1 / 0.5,1 / 1,1 / 2$, and $1 / 4$ were obtained. From these composition-controlled colloids, 12 carbon-supported catalysts were prepared. The catalysts were denoted as $\mathrm{PdxAgy/C}(\mathrm{z})$ attending to the composition of the nanoparticles (" $\mathrm{x}$ " and " $\mathrm{y}$ " related to the $\mathrm{Pd} / \mathrm{Ag}$ molar ratio, and " $\mathrm{z}$ " indicating the $\mathrm{PVP} / \mathrm{metal}$ molar ratio). The catalytic activity of the samples was assessed by means of gas chromatography by following the hydrogen generated after $3 \mathrm{~h}$ of reaction at $30^{\circ} \mathrm{C}$, and the results are summarized in Figure 4.

All catalysts showed $\sim 100 \%$ of selectivity toward the formic acid dehydrogenation reaction so that the generation of CO through formic acid dehydration was suppressed. The catalytic activity was shown to be strongly dependent on the composition of the nanoparticles, both $\mathrm{Pd} / \mathrm{Ag}$ molar ratio and PVP content. It was observed that the incorporation of $\mathrm{Ag}$ in the catalysts greatly enhanced the activity, reaching the optimum activity for those samples with a $\mathrm{Pd} / \mathrm{Ag}$ of $1 / 2$ for most of the PVP contents. However, the catalytic activity decayed dramatically for those samples with the highest $\mathrm{Ag}$ content ( $\mathrm{Pd} / \mathrm{Ag}$ of $1 / 4)$. Among all catalysts investigated, sample $\mathrm{Pd} 1 \mathrm{Ag} 2 / \mathrm{C}(1)$ was the most active and the beneficial effect from the addition of $\mathrm{Ag}$ was also confirmed by the comparison with the $\mathrm{Pd}$ monometallic counterpart catalyst (the $\mathrm{H}_{2}$ production after $3 \mathrm{~h}$ of reaction was 266 and 144 $\mu \mathrm{mol}$ for $\mathrm{Pd} 1 \mathrm{Ag} 2 / \mathrm{C}(1)$ and $\mathrm{Pd} / \mathrm{C}$, respectively, under identical experimental conditions).

Once the best-performing catalyst was identified, its applicability in a large-scale reactor was also checked by using a burette system equipped with a reflux condenser, so that

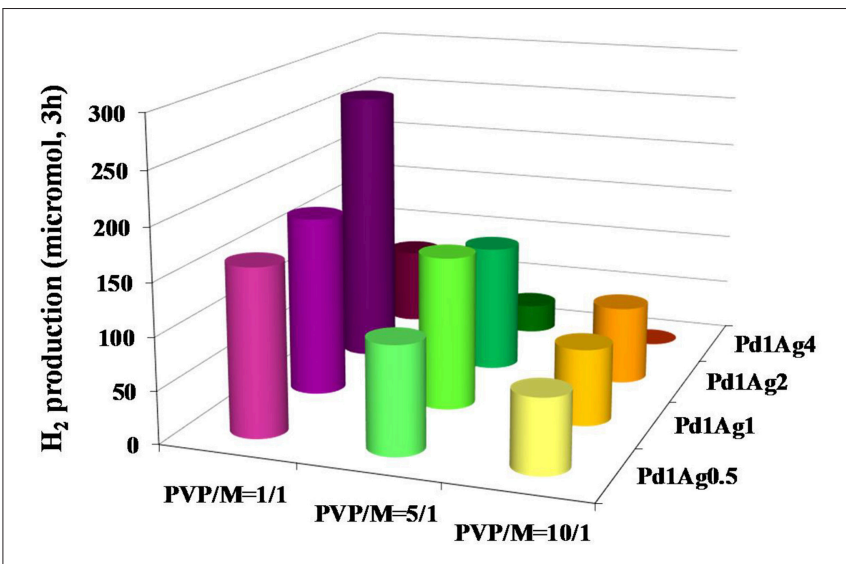

FIGURE 4 | $\mathrm{H}_{2}$ generated after $3 \mathrm{~h}$ of reaction over $\mathrm{PdAg} / \mathrm{C}$ catalysts with a various composition of the nanoparticles. Adapted with permission from Navlani-García et al. (2016c). Copyright 2016 American Chemical Society.

the hydrogen generation could be measured by observing the volume of gas displaced. A reaction rate of 3,000 $\mathrm{mL} \mathrm{min}^{-1} \mathrm{~g}_{\mathrm{Pd}}^{-1}$ was achieved, confirming the suitability of the studied catalysts. Furthermore, Pd1Ag2/C(1) showed a TOF value of $855 \mathrm{~h}^{-1}$ (on the basis of Pd content), which was higher than those values achieved by other bimetallic PdAg catalysts previously reported in the literature (Tedsree et al., 2011; Liu et al., 2016).

As for the effect of PVP, it was seen that the catalytic performance decayed as the capping agent content increased, which was initially ascribed to either change in the surface composition of the nanoparticles and electronic effect exerted by the PVP molecules, or changes in the size of the nanoparticles. In order to ascertain the relationship between the composition of the nanoparticles and their activity, the catalysts were thoroughly characterized.

The result of TEM analysis indicated that similar average nanoparticle size was obtained for those catalysts with $\mathrm{Pd} / \mathrm{Ag}$ of $1 / 0.5,1 / 1$, and $1 / 2$, (sizes ranging from 3.0 to $3.9 \mathrm{~nm}$ ) regardless the PVP content (see Table 3 ). Furthermore, it was shown that the addition of $\mathrm{Ag}$ in the nanoparticles resulted in smaller nanoparticles as compared to the Pd monometallic counterpart catalysts. That fact was related to the favored reduction of $\mathrm{Pd}$ ions when $\mathrm{Ag}$ ions were present, which would lead to a larger number of seeds in the nucleation step and would eventually produce nanoparticles with a smaller size. As for the catalysts with larger $\mathrm{Ag}$ content ( $\mathrm{Pd} / \mathrm{Ag}$ of $1 / 4$ ), the average size of the nanoparticles was larger, particularly in the samples with lower PVP content $(5.0,4.0$, and $3.6 \mathrm{~nm}$ for Pd1Ag4/C(1), Pd1Ag4/C(5), and Pd1Ag4/C(10) catalysts, respectively). Furthermore, some aggregates were detected in sample Pd1Ag4/C(10), which was ascribed to the high PVP content and concentration of metal precursors used in the synthesis of the corresponding colloid.

HR-TEM analysis was also performed for a representative colloid (Pd1Ag2, with a PVP/metal ratio of $1 / 1$ ) and the lattice space was measured to be $0.23 \mathrm{~nm}$, between the (111) lattice spacing of fcc (face-centered cubic) $\mathrm{Pd}(0.224 \mathrm{~nm})$ 
TABLE 3 | Particle size determined by TEM analysis ( $\mathrm{d}_{\text {TEM }}$ ) for all catalysts.

\begin{tabular}{|c|c|c|c|}
\hline Sample & $\mathrm{d}_{\text {TEM }}(\mathrm{nm})$ & Sample & $\mathrm{d}_{\text {TEM }}(\mathrm{nm})$ \\
\hline $\mathrm{Pd} 1 \mathrm{Ag} 0.5 / \mathrm{C}(1)$ & $3.9 \pm 0.8$ & $\mathrm{Pd1Ag2/C(1)}$ & $3.5 \pm 0.9$ \\
\hline Pd1Ag0.5/C(5) & $3.4 \pm 0.7$ & Pd1Ag2/C(5) & $3.0 \pm 0.6$ \\
\hline $\mathrm{Pd1Ag0.5/C(10)}$ & $3.4 \pm 0.6$ & $\mathrm{Pd1Ag2/C}(10)$ & $3.1 \pm 0.8$ \\
\hline $\mathrm{Pd1Ag1/C(1)}$ & $3.6 \pm 0.9$ & $\mathrm{Pd} 1 \mathrm{Ag} 4 / \mathrm{C}(1)$ & $5.0 \pm 3.0$ \\
\hline Pd1Ag1/C(5) & $3.3 \pm 0.6$ & $\mathrm{Pd1Ag4/C(5)}$ & $4.0 \pm 1.1$ \\
\hline $\mathrm{Pd1Ag1/C(10)}$ & $3.4 \pm 0.6$ & $\mathrm{Pd} 1 \mathrm{Ag} 4 / \mathrm{C}(10)$ & $3.6 \pm 1.0$ \\
\hline
\end{tabular}

Adapted with permission from Navlani-García et al. (2016c). Copyright 2016 American Chemical Society.

and $\mathrm{Ag}(0.235 \mathrm{~nm})$, which suggested the presence of alloyed nanoparticles.

The set of catalysts that displayed the highest activity among investigated $\mathrm{Pd} 1 \mathrm{Ag} 2 / \mathrm{C}$ samples were characterized by XAFS analysis. As can be seen in Figure 5, the Fourier transformation (FT) of $k^{3}$-weighted extended X-ray absorption fine structure (EXAFS) spectra of the reference samples (Pd and Ag foils), displayed peaks centered at 2.5 and $2.7 \AA$, respectively (Figures 5A,B), corresponding to metal-metal bonding ( $\mathrm{Pd}-\mathrm{Pd}$ and Ag-Ag, respectively). In the case of the catalysts, those peaks were shifted as compared to the references, confirming the presence of heteroatomic Pd-Ag bonding in the nanoparticles.

The electronic structure of these catalysts was also analyzed by means of XPS and, even though both $\mathrm{Pd}$ and $\mathrm{Ag}$ were mainly in their metallic form, oxidized forms were also detected. Such species were related to the metal-PVP interaction via $\mathrm{C}=\mathrm{O}$ groups of the polymer molecules. Then, the presence of $\mathrm{Pd}(\mathrm{II})$ and $\mathrm{Ag}(\mathrm{I})$ species in the nanoparticles was related to the presence of PVP molecules. Furthermore, the charge transfer from Ag to Pd was also considered. It was observed that such charge transfer was hampered for high PVP content in the nanoparticles, which was due to its capping effect on the Ag species. It was found that the PVP content greatly affected the surface composition of the nanoparticles, as higher Pd/Ag surface ratio was detected as the PVP content in the nanoparticles decreased (surface $\mathrm{Pd} / \mathrm{Ag}$ ratio of $1.26,1.20$, and 0.78 for $\mathrm{Pd} 1 \mathrm{Ag} 2 / \mathrm{C}(1), \mathrm{Pd} 1 \mathrm{Ag} 2 / \mathrm{C}(5)$, and $\mathrm{Pd} 1 \mathrm{Ag} 2 / \mathrm{C}(10)$, respectively), which was associated with the relative interaction ability of $\mathrm{Pd}$ and Ag with the polymer molecules.

In view of the characterization results, the catalytic tendency displayed by the set of samples were discussed. First, it was claimed that the poor performance displayed by the Pd1Ag4 set of catalysts could be due to the aggregation found in those samples. However, that aspect did not determine the tendency observed for the other three sets of catalysts (Pd1Ag0.5, Pd1Ag1, and $\mathrm{Pd} 1 \mathrm{Ag} 2$ ) because of the very similar average nanoparticle size observed in those samples. The detailed characterization of $\mathrm{Pd} 1 \mathrm{Ag} 2 / \mathrm{C}$ set of samples by means of XPS analysis revealed that the $\mathrm{PVP} /$ metal molar ratio present in the catalysts had an important effect on the features of the catalysts, in terms of surface Pd enrichment in the nanoparticles and electronic density in the Pd atoms which, along with an optimum composition of the nanoparticles (i.e., Pd/Ag molar ratio), were shown to be the determining aspects for controlling the catalytic activity.

\section{Pd-Catalysts Supported on Nitrogen-Doped Carbon Xerogels}

Even though the design of catalysts is usually focused on tailoring the active phase features, in terms of nanoparticles size, shape, composition and so forth (García-Aguilar et al., 2016b; NavlaniGarcía et al., 2016b,c), the impact of the support characteristics in the final catalytic performance toward the hydrogen production from the formic acid dehydrogenation reaction has merited several investigations and various approaches, in which either the incorporation of additional functional groups or the intrinsic support features were assessed, can be found in the literature. For instance, the local basicity of the support has been pointed out as an important parameter to enhance the formic acid dehydrogenation reaction, as such basic groups can either influence the final electronic density of metallic active sites or directly participate as hydrogen scavengers (Mori et al., 2014, 2015, 2017a; Masuda et al., 2018). At this point, carbon materialbased catalysts have been considered as a promising alternative to attain competitive hydrogen production abilities because their basicity can be easily modified by nitrogen functionalization (Bashkova et al., 2003; Bagreev et al., 2004; Hulicova-Jurcakova et al., 2009). Hence, some experimental studies combined with theoretical calculations have tried to shed some light on the understanding of the nitrogen effect on active sites in the formic acid dehydrogenation reaction. Recently, an interesting study about $\mathrm{N}$-doped mesoporous carbon-supported Pd species demonstrated that the interaction between single isolated $\mathrm{Pd}^{2+}$ cations and pyridinic nitrogen groups boosted the formic acid dehydrogenation reaction as compared to the $\mathrm{N}$-free counterpart catalyst (Bulushev et al., 2016b). Furthermore, the nitrogen functionalization present on carbon materials has been found to be anchoring points for metal nanoparticles, which results in small and well-distributed nanoparticles on the surface of the catalysts and enhanced catalytic performances (Jeon et al., 2016).

We recently studied the effect of the nitrogen doping level on the catalytic ability in the formic acid dehydrogenation reaction over Pd-based N-doped carbon catalysts (Navlani-García et al., 2019). To do this, carbon xerogels were chosen as carbon support, in which apart from fixing the nitrogen doping level, the porous texture could also be modulated by modifying the synthesis conditions. The control of the pore texture allowed us to design catalysts that gathered both an accessible porous structure and nitrogen groups, which could facilitate homogenous dispersion of small nanoparticles on the surface of the catalysts. In that study, N-doped carbon xerogels were prepared by a polycondensation method of resorcinol and formaldehyde in the presence of melamine using the same protocol as it was reported in a previous work (Salinas-Torres et al., 2018). All supports were characterized by both $\mathrm{N}_{2}$ adsorption-desorption isotherms and mercury porosimetry measurements to gain knowledge about the pore texture (see Table 4) as well as elemental analysis and XPS to know the nitrogen content and nitrogen functionalities, respectively. The supports were denoted as $\mathrm{Pd} / \mathrm{aN}-\mathrm{CX}-\mathrm{b}$ to distinguish the nitrogen doping level (a) and the pore texture (b) in each sample. All supports had micropores related to the gas uptake at low $\mathrm{P} / \mathrm{P}_{0}$ observed in the $\mathrm{N}_{2}$ isotherms. Moreover, these 


\section{A} Pd FT-EXAFS

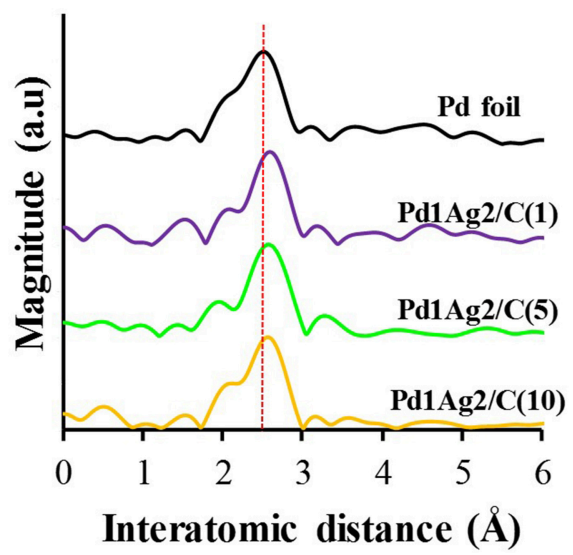

B Ag FT-EXAFS

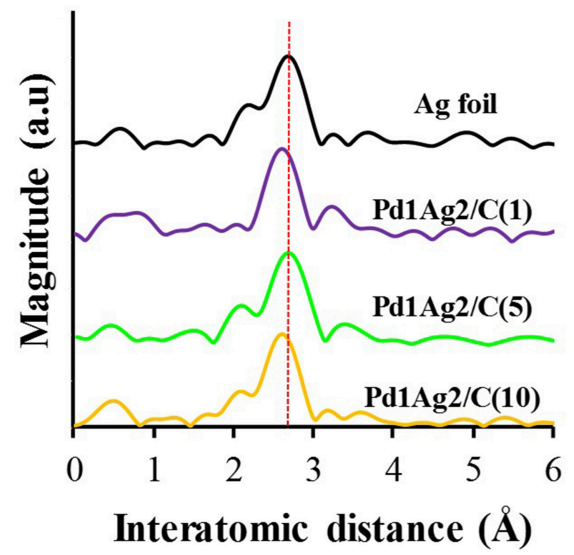

FIGURE 5 | (A) Pd and (B) Ag FT-EXAFS spectra of Pd1Ag2/C catalysts prepared using colloids with different PVP/M ratios [Pd1Ag2/C(1), Pd1Ag2/C(5), and Pd1Ag2/C(10)] and reference samples (Pd and Ag foils). Adapted with permission from (Navlani-García et al., 2016c). Copyright 2016 American Chemical Society.

TABLE 4 | Porous texture properties for $N$-doped carbon xerogels supports.

\begin{tabular}{lcccc}
\hline Support & $\begin{array}{c}\mathbf{S}_{\mathbf{B E T}} \\
\left(\mathbf{m}^{\mathbf{2}} \mathbf{g}^{-\mathbf{1}}\right)\end{array}$ & $\begin{array}{c}\mathbf{V}_{\mathbf{D R}} \\
\left(\mathbf{c m}^{\mathbf{3}} \mathbf{g}^{-\mathbf{1}}\right)\end{array}$ & $\begin{array}{c}\mathbf{V}_{\mathbf{V}} \\
\left(\mathbf{c m}^{\mathbf{3}} \mathbf{g}^{-\mathbf{1}}\right)\end{array}$ & $\begin{array}{c}\text { Pore } \\
\text { size }(\mathbf{n m})\end{array}$ \\
\hline CX-meso & 726 & 0.29 & 1.46 & 16 \\
2N-CX-meso & 545 & 0.22 & 0.46 & 6 \\
4N-CX-meso & 590 & 0.24 & 0.94 & 14 \\
4N-CX-macro & 587 & 0.24 & 1.60 & 1,180 \\
8N-CX-macro & 307 & 0.13 & 0.65 & - \\
\hline
\end{tabular}

Adapted with permission from Navlani-García et al. (2019). Copyright 2019 Elsevier.

$\mathrm{N}$-doped carbon xerogels also presented volume of mesopores or macropores as well as different average pore size depending on the precursors' solution selected (Table 4).

Subsequently, a wet impregnation method was used to synthesize their Pd-based N-doped carbon catalyst counterparts (Pd/support). Afterwards, the particle size of the as-synthesized catalysts was analyzed by TEM (see Figure 6). From the histograms, it was observed that the average nanoparticle size ranged from 2.2 to $3.4 \mathrm{~nm}$ for most of the samples. However, $\mathrm{Pd} / 8 \mathrm{~N}-\mathrm{CX}$-macro micrograph revealed the formation of large nanoparticles with non-regular shapes and with an average nanoparticle size of $8.3 \mathrm{~nm}$, which were not well-distributed on the support. This fact could be associated with both the high concentration of Lewis basic sites and the lowest apparent surface area for $8 \mathrm{~N}$-CX-macro support. On the contrary, the rest of the catalysts, which had lower nitrogen content than $8 \mathrm{~N}$-CX-macro support, displayed good dispersion of sphericalshaped nanoparticles. It is important to mention that $\mathrm{Pd} / \mathrm{CX}$ meso support ( $N$-free sample) exhibited the largest average nanoparticle size $(3.4 \mathrm{~nm})$, excluding $8 \mathrm{~N}$-CX-macro support. Therefore, according to that result, the nitrogen doping level was a crucial parameter to produce both small and well-dispersed nanoparticles, provided that the nitrogen doping level did not surpass a specific amount.

The electronic state of Pd nanoparticles was analyzed by XPS measurements. Taking into account the position of the binding energies of $\mathrm{Pd} 3 \mathrm{~d}$ peaks for $\mathrm{Pd}$-based $\mathrm{N}$-doped carbon catalysts compared to the $\mathrm{N}$-free catalyst, the existence of $\mathrm{Pd}-\mathrm{N}$ interaction was concluded. Regarding the nitrogen groups, XPS spectra for both $\mathrm{N}$-carbon xerogel supports and their Pd-based catalyst counterparts revealed that pyridinic and quaternary $N$ groups were the most abundant, although pyrrolic/pyridone nitrogen groups were also observed. X-ray absorption measurements were completed to gain a better understanding of the electronic state of Pd. From EXAFS analysis (see Figure 7), it was demonstrated that all catalysts presented $\mathrm{Pd}$ in the metallic state $(2.5 \AA)$. Furthermore, the peak ascribed to the Pd-N interaction (1.6 $\AA$ ) was also observed for the N-containing catalysts, with the exception of the $\mathrm{Pd} / 8 \mathrm{~N}-\mathrm{CX}$-macro catalyst. This weak $\mathrm{Pd}-\mathrm{N}$ interaction could be attributed to the difficult accessibility of Pd nanoparticles to the nitrogen functionalities due to the low apparent surface area of the $\mathrm{Pd} / 8 \mathrm{~N}-\mathrm{CX}$-macro catalyst. Furthermore, the less important Pd-N interaction could also be responsible for the larger nanoparticles observed in that sample. The existence of $\mathrm{PdO}$ in the samples could not be discarded because the corresponding peak appears at the same interatomic distance as that of the Pd-N bond.

After characterization of all catalysts, the catalytic activity was evaluated by monitoring the gas evolved $\left(\mathrm{H}_{2}+\mathrm{CO}_{2}\right)$ in a burette system, immediately after the addition of a solution that consisted of formic acid and sodium formate (molar ratio $=9: 1$ ). Figure 8 depicts the gas generated for all samples as well as the TOF values calculated after $10 \mathrm{~min}$ of reaction. It was observed that the catalytic ability in the formic acid dehydrogenation reaction not only depended on the nitrogen doping level, but the pore texture also played a key role in the catalytic performance. For instance, the volume of gas produced by the 


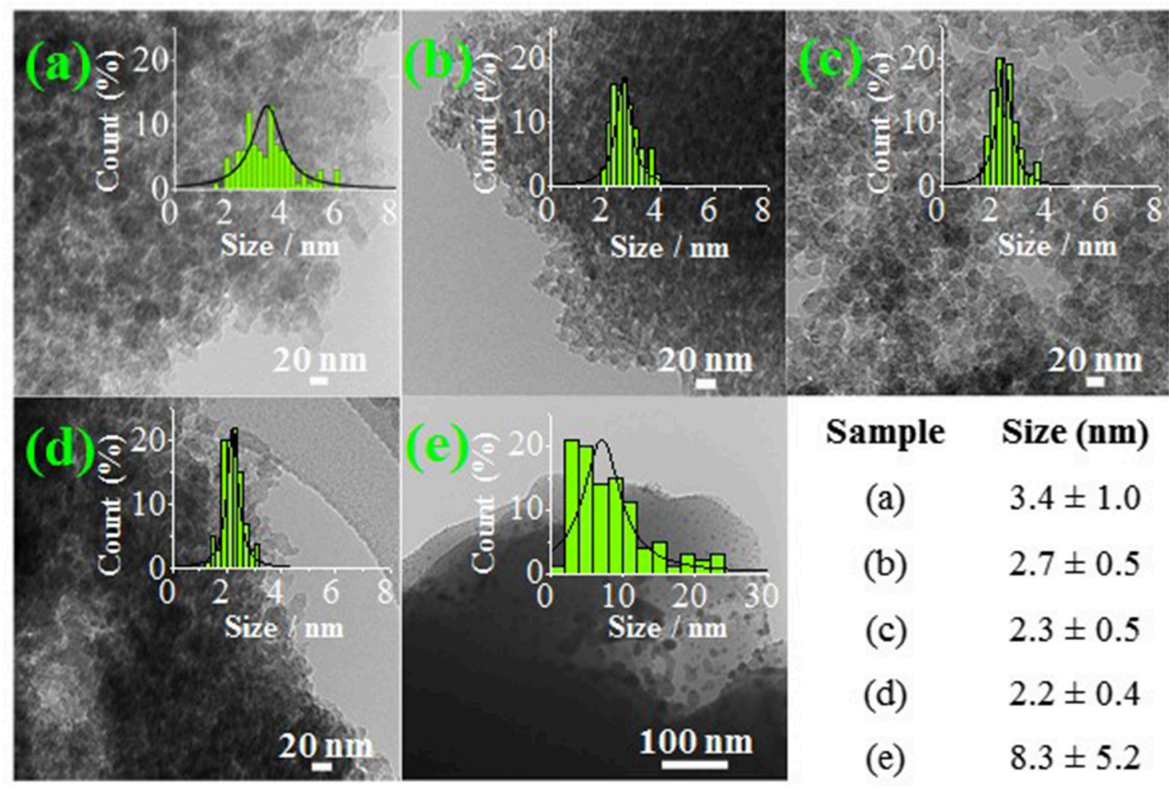

FIGURE 6 | TEM micrographs of catalysts: (a) Pd/CX-meso, (b) Pd/2N-CX-meso, (c) Pd/4N-CX-meso, (d) Pd/4N-CX-macro, (e) Pd/8N-CX-macro. Adapted with permission from Navlani-García et al. (2019). Copyright 2019 Elsevier.

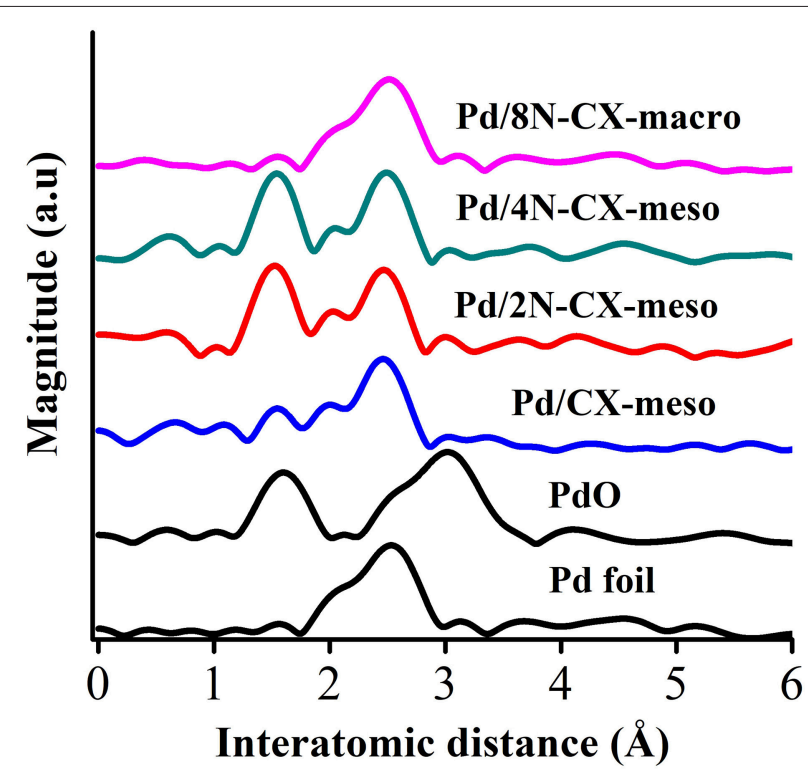

FIGURE 7 | Pd K-edge FT-EXAFS spectra for all catalysts, and Pd foil and $\mathrm{PdO}$ as reference samples. Adapted with permission from Navlani-García et al. (2019). Copyright 2019 Elsevier.

Pd/4N-CX-meso catalyst was almost three times that obtained from the $\mathrm{Pd} / 4 \mathrm{~N}-\mathrm{CX}$-macro. Moreover, despite the fact that the $\mathrm{Pd} / \mathrm{CX}$-meso catalyst did not contain nitrogen, it showed almost the same behavior as the $\mathrm{Pd} / 8 \mathrm{~N}-\mathrm{CX}$-macro catalyst. However, it is important to note that all $\mathrm{Pd}$-based $\mathrm{N}$-doped carbon xerogel catalysts, with the exception of the $\mathrm{Pd} / 8 \mathrm{~N}$-CX-macro catalyst, displayed enhanced catalytic performance as compared to the N-free sample. Regarding the catalysts with micromesoporous texture and different nitrogen doping level, the $\mathrm{Pd} / 2 \mathrm{~N}$-CX-meso catalyst showed poorer catalytic ability in the formic acid dehydrogenation reaction than $\mathrm{Pd} / 4 \mathrm{~N}-\mathrm{CX}$-meso catalysts, indicating that nitrogen content must be regarded as an important parameter to control the catalytic abilities in the present application. According to the tendency observed, it was concluded that a nitrogen content higher than $4 \mathrm{wt} \%$ favored the formation of larger nanoparticles $(8.3 \mathrm{~nm})$ and non-homogenous dispersion on the support, and therefore the catalytic activity in the formic acid dehydrogenation reaction dropped drastically compared to the other Pd-based N-doped carbon catalysts.

In light of these results, it was concluded that the improvement of the catalytic ability could not be only attributed to the nitrogen content, since the Pd electronic state as well as the basicity and the pore texture of the support material should be considered. This is because those factors can influence the interaction with formic acid or reaction intermediates, which in turn is one of the most important aspects involved in the formic acid dehydrogenation reaction (Kim et al., 2018).

Unlikely most of the previous studies reported, it was therein demonstrated that not only was the presence of specific nitrogen functionalities important to achieving high-performing catalysts, but the nitrogen doping level in carbon materials with tuned porosity was also a crucial aspect for attaining good catalytic activities in the formic acid dehydrogenation reaction. A promising initial TOF value of $2,014 \mathrm{~h}^{-1}$ on the basis of the total Pd amount was obtained for the most active catalyst among those investigated. These findings could serve as a platform for the design of $\mathrm{N}$-doped carbon materials with controlled porosity and active basic sites in order to foster the catalytic 


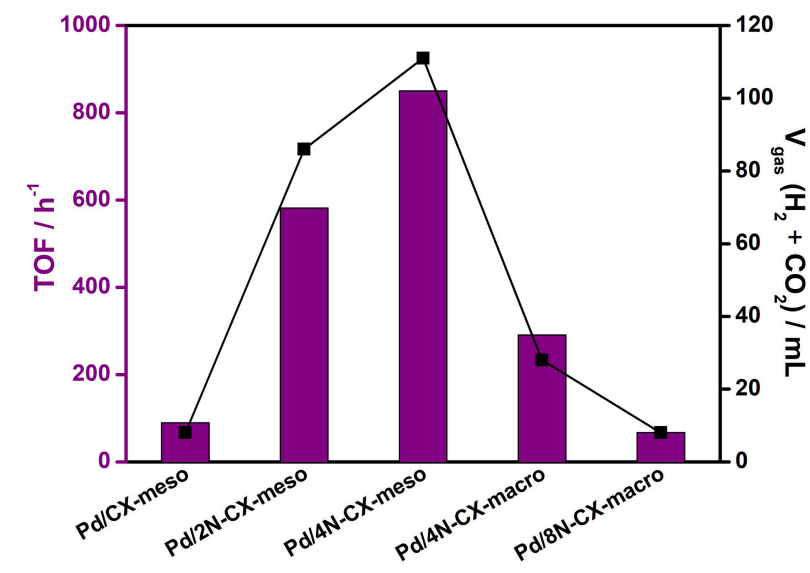

FIGURE 8 | TOF (calculated at 10 min of reaction) and $\mathrm{V}_{\text {gas }}\left(\mathrm{H}_{2}+\mathrm{CO}_{2}\right)$ generated from the formic acid dehydrogenation reaction $\left(75^{\circ} \mathrm{C}\right)$. performance in the hydrogen generation from the formic acid dehydrogenation reaction.

\section{Pd-Catalysts Supported on Graphitic Carbon Nitride}

The latter sections summarized some of our recent studies on carbon-supported catalysts for the formic acid dehydrogenation reaction by using both commercial activated carbon and synthetized nitrogen-doped carbon xerogels. In the present section, our study on carbon nitride-supported catalysts is included because, although the structure and properties of graphitic carbon nitride $\left(\mathrm{g}-\mathrm{C}_{3} \mathrm{~N}_{4}\right)$ significantly differ from those of conventional carbon materials (Inagaki et al., 2019), it could be considered as a C-N-based material analogous to graphite because of its layered structure (Wang et al., 2012). It might also be of interest for those readers interested in carbonrelated materials.

Motivated by the promising results obtained in our study on $\mathrm{N}$-doped carbon xerogels (Navlani-García et al., 2019) and other investigations on the impact of the nitrogen functionalization on carbon materials for their use as support in the formic acid dehydrogenation reaction (Bulushev et al., 2016a; Masuda et al., 2018), along with the outstanding role attributed to g$\mathrm{C}_{3} \mathrm{~N}_{4}$ in stabilizing small metal nanoparticles (Zhu J. et al., 2014; Bhowmik et al., 2015; Wu et al., 2017), our recent study was focused on the development of g- $\mathrm{C}_{3} \mathrm{~N}_{4}$-supported catalysts (Navlani-García et al., 2018b). In that case, PdCo bimetallic nanoparticles with various compositions were used as active phase, while the role of $g-\mathrm{C}_{3} \mathrm{~N}_{4}$ as catalytic support for this application was pointed out by comparison with standard supports based on carbon materials (i.e., carbon black and activated carbon) and oxides (i.e., $\mathrm{CeO}_{2}, \mathrm{Al}_{2} \mathrm{O}_{3}$, and $\mathrm{TiO}_{2}$ ). It should be mentioned that, as it was previously commented, most of the bimetallic or multimetallic Pd-based heterogeneous catalysts used in this application are composed of noble-metal active phases. In the study on PdCo catalysts mentioned above, the incorporation of a non-noble metal element in the catalysts

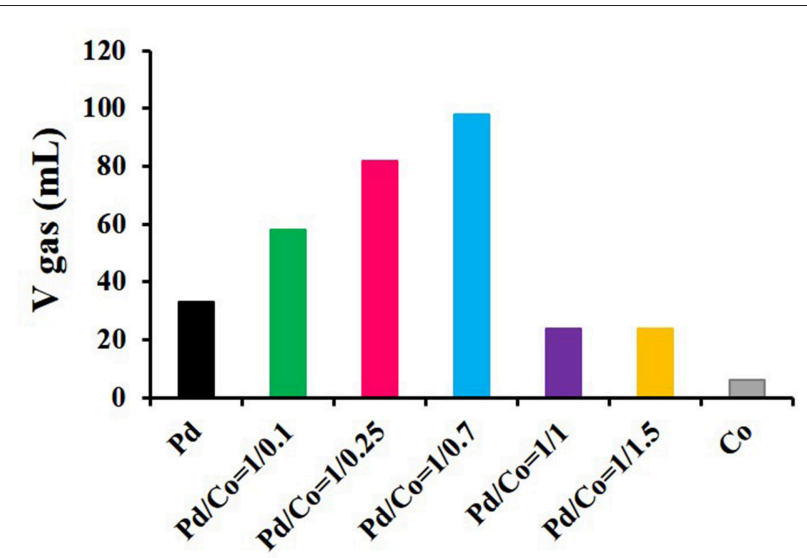

FIGURE 9 | Gas generated after $1 \mathrm{~h}$ of reaction at $75^{\circ} \mathrm{C}$ for the $\mathrm{PdCo} / \mathrm{g}-\mathrm{C}_{3} \mathrm{~N}_{4}$ set of catalysts along with $\mathrm{Pd}$ and Co monometallic counterparts.

was selected as an interesting strategy to reduce the final cost of the resulting materials.

In order to optimize the composition of the catalysts, g$\mathrm{C}_{3} \mathrm{~N}_{4}$, previously obtained from thermal decomposition of dicyandiamide, was simultaneous impregnated with different proportions of the precursors of $\mathrm{Pd}$ and $\mathrm{Co}$ (i.e., $\mathrm{Na}_{2} \mathrm{PdCl}_{4}$ and $\left.\mathrm{Co}\left(\mathrm{NO}_{3}\right)_{2}\right)$ and subsequently reduced with $\mathrm{NaBH}_{4}$, so as to prepare catalysts with fixed $\mathrm{Pd}$ loadings and various Pd-to-Co molar ratios of $1 / 0.1,1 / 0.25,1 / 0.7,1 / 1$, and $1 / 1.5$. As in the former study, the performance of the catalysts at $75^{\circ} \mathrm{C}$ was assessed by monitoring the gas generation $\left(\mathrm{H}_{2}+\right.$ $\mathrm{CO}_{2}$ ) in a burette system after adding a solution containing formic acid and sodium formate in a molar ratio of 9 to 1 (see Figure 9). It was observed that the activity strongly depended on the composition of the nanoparticles and a marked enhancement was evidenced by the bimetallic nanoparticles as compared to the monometallic catalysts, both $\mathrm{Pd} / \mathrm{g}-\mathrm{C}_{3} \mathrm{~N}_{4}$ and $\mathrm{Co} / \mathrm{g}-\mathrm{C}_{3} \mathrm{~N}_{4}$. The optimum composition of the nanoparticles among those investigated was found in the $\mathrm{PdCo} / \mathrm{g}-\mathrm{C}_{3} \mathrm{~N}_{4}$ (1/0.7) catalyst, which showed a TOF value of $1,193 \mathrm{~h}^{-1}$, calculated on the basis of Pd. It was observed that the catalysts with higher Co content were less active in the formic acid dehydrogenation reaction, which was initially ascribed to the Co-rich surface of the nanoparticles and its low activity in the present application.

The best performing catalyst $\left[\mathrm{PdCo} / \mathrm{g}-\mathrm{C}_{3} \mathrm{~N}_{4}(1 / 0.7)\right]$ was compared with various catalysts prepared with the same composition of the metallic active phase $(\mathrm{Pd} / \mathrm{Co}=1 / 0.7)$ and some traditional supports with higher apparent surface area $\left(S_{B E T}=7,241,995,125,189\right.$, and $46 \mathrm{~m}^{2} \mathrm{~g}^{-1}$ for $\mathrm{g}$ $\mathrm{C}_{3} \mathrm{~N}_{4}$, carbon black, activated carbon, $\mathrm{CeO}_{2}, \mathrm{Al}_{2} \mathrm{O}_{3}$, and $\mathrm{TiO}_{2}$, respectively). The much higher catalytic ability for the formic acid dehydrogenation reaction displayed by $\mathrm{PdCo} / \mathrm{g}-\mathrm{C}_{3} \mathrm{~N}_{4}(1 / 0.7)$ highlighted the suitability of $g-\mathrm{C}_{3} \mathrm{~N}_{4}$ for the present application because of its role in anchoring the metal nanoparticles and possible direct participation in the dehydrogenation reaction through the nitrogen atoms present on its structure. 
To shed some light on the behavior observed in the catalytic systems, detailed characterization of the catalysts was performed by both experimental techniques and density functional theory (DFT) calculations. After confirming the intact structure of the catalysts by XRD analysis and the composition of the nanoparticles by ICP, TEM micrographs were recorded to determine the average nanoparticle size of some of the selected catalysts. The average nanoparticle size was determined to be 3.8, 2.5, 2.3, and $9.1 \mathrm{~nm}$ for $\mathrm{Pd} / \mathrm{g}-\mathrm{C}_{3} \mathrm{~N}_{4}, \mathrm{PdCo} / \mathrm{g}-\mathrm{C}_{3} \mathrm{~N}_{4}(1 / 0.7)$, $\mathrm{PdCo} / \mathrm{g}-\mathrm{C}_{3} \mathrm{~N}_{4}(1 / 1)$, and $\mathrm{PdCo} /$ activated carbon (1/0.7), which pointed out the role of both the addition of $\mathrm{Co}$ in the nanoparticles and the importance of $\mathrm{g}-\mathrm{C}_{3} \mathrm{~N}_{4}$, in the synthesis of small and well-distributed nanoparticles, which ultimately had an impact on the catalytic activity.

XPS analysis was used to investigate the electronic properties of the catalysts. A marked shift toward lower binding energy values was observed in $\mathrm{Pd} 3 \mathrm{~d}$ spectra of $\mathrm{PdCo} / \mathrm{g}-\mathrm{C}_{3} \mathrm{~N}_{4}$ samples as compared to $\mathrm{Pd} / \mathrm{g}-\mathrm{C}_{3} \mathrm{~N}_{4}$, which was attributed to the presence of electron-rich $\mathrm{Pd}$ species in the alloyed PdCo nanoparticles due to the different electronegativity value of both elements (1.9 and 2.2, in Pauling units, for Co and $\mathrm{Pd}$, respectively). It should be mentioned that, according to several studies, such electron-rich Pd species are crucial for catalyzing the formic acid dehydrogenation reaction. For comparison purposes, bimetallic catalysts based on other supports (carbon black, activated carbon, $\mathrm{CeO}_{2}, \mathrm{Al}_{2} \mathrm{O}_{3}$, and $\mathrm{TiO}_{2}$ ) were also analyzed by XPS but in those cases the $\mathrm{Pd}-\mathrm{Co}$ interaction was not shown to be as obvious as in the case of $\mathrm{PdCo} / \mathrm{g}-\mathrm{C}_{3} \mathrm{~N}_{4}$, suggesting that the formation of alloyed nanoparticles on those supports might be less favored and that $\mathrm{g}-\mathrm{C}_{3} \mathrm{~N}_{4}$ was a suitable catalytic support for the anchoring of metal precursors and subsequent formation of bimetallic nanoparticles.

Furthermore, the charge transfer from Co to $\mathrm{Pd}$ found experimentally for the $\mathrm{PdCo} / \mathrm{g}-\mathrm{C}_{3} \mathrm{~N}_{4}$ catalysts was confirmed by theoretical calculation using DFT analysts with $\mathrm{Pd}_{43}$ and $\mathrm{Pd}_{22} \mathrm{Co}_{21}$ clusters as models of $\mathrm{Pd}$ and PdCo nanoparticles, respectively. As is evidenced by the Mulliken atomic charges represented in Figure 10, the surface Pd atoms of the PdCo model were negatively charged as compared to those of the monometallic Pd cluster, while Co atoms had a positive charge because of the charge transfer to Pd atoms in the alloyed system.

In addition, XAFS measurements were also conducted to get more information about the PdCo alloying effect and the support-metal interaction through the nitrogen function group of $\mathrm{g}-\mathrm{C}_{3} \mathrm{~N}_{4}$ by analyzing some selected $\mathrm{PdCo} / \mathrm{g}-\mathrm{C}_{3} \mathrm{~N}_{4}$ and $\mathrm{PdCo} /$ activated carbon catalysts. FT-EXAFS spectra of the $\mathrm{PdCo} / \mathrm{g}-\mathrm{C}_{3} \mathrm{~N}_{4}$ catalysts analyzed displayed two main peaks at 1.6 and $2.5 \AA$, which were related to the presence of $\mathrm{Pd}-\mathrm{O}$ (and/or Pd-N) and metal Pd-Pd bonds, respectively. Concerning the first peak (at $1.6 \AA$ ), it should be mentioned that the features of the catalysts in terms of small nanoparticles size and abundant nitrogen content of the support complicated its assignation to either $\mathrm{Pd}-\mathrm{N}$ or $\mathrm{Pd}-\mathrm{O}$, because both bonds might exist in the samples. It should be mentioned that the Pd-Co bond $(\sim 2.2 \AA)$ could not be clearly detected in the $\mathrm{Pd}$ spectrum because the corresponding peak might be

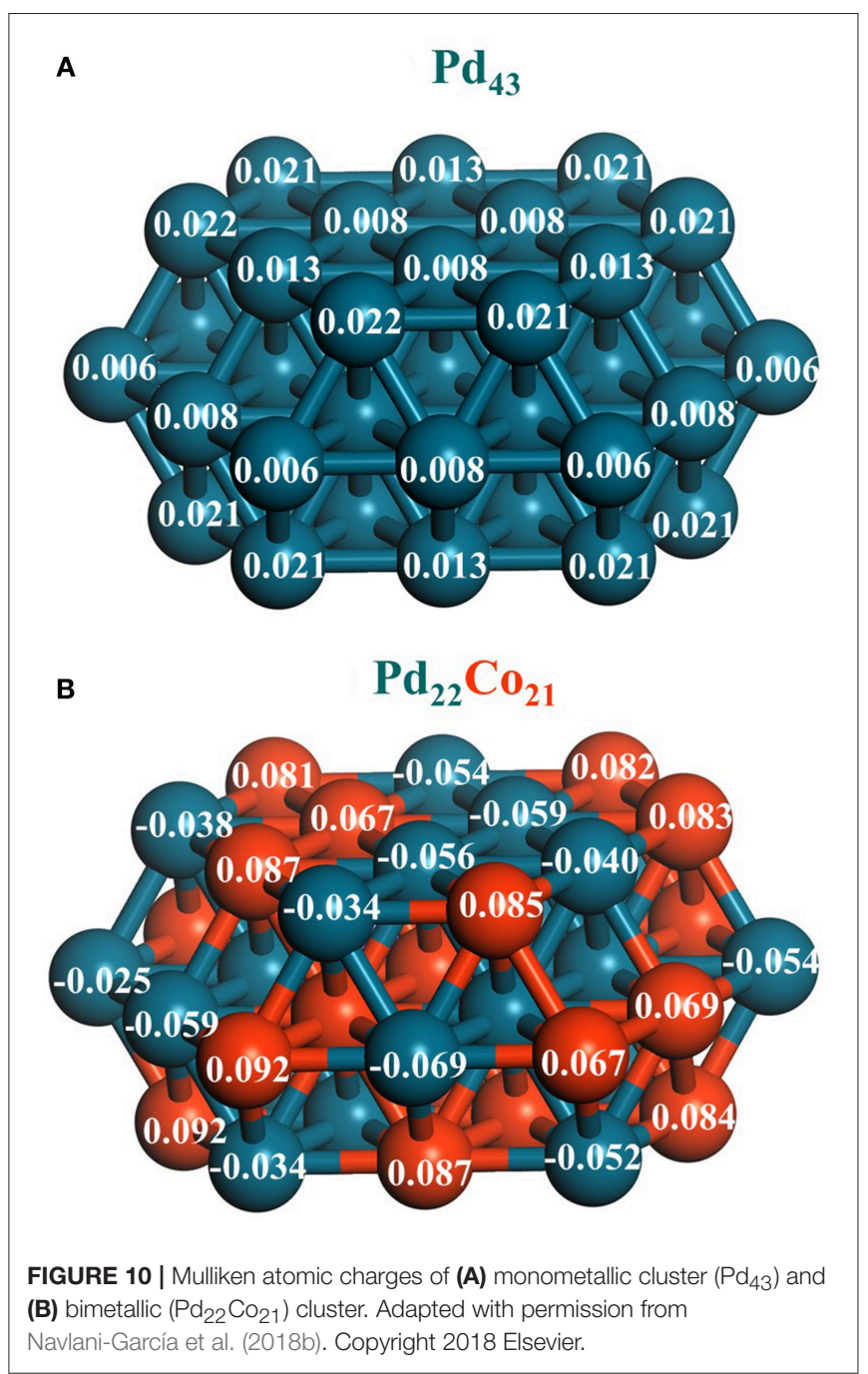

overlapping with some other peak, but the contribution of Pd-Co bond was detected in the Co spectra, which appeared along with the contribution of Co-O and Co-Co bonds (located at 1.7 and $2.7 \AA$, respectively). This once again confirmed the presence of alloyed nanoparticles in the catalysts. Unlike the $\mathrm{g}-\mathrm{C}_{3} \mathrm{~N}_{4}$-supported catalysts, such peak assigned to the $\mathrm{Pd}$ Co bond was not observed for the catalyst supported on activated carbon, revealing that alloyed PdCo nanoparticles might not exist in the $\mathrm{PdCo} /$ activated carbon catalyst but segregated $\mathrm{Pd}$ and $\mathrm{Co}$ species might exist instead, which again corroborated the importance of the support in affording alloyed nanoparticles.

At that point of the study, it was determined that the enhanced performance observed by the bimetallic systems, in particular for $\mathrm{PdCo} / \mathrm{g}-\mathrm{C}_{3} \mathrm{~N}_{4}(1 / 0.7)$, was due to the positive impact of both features of the nanoparticles (size and distribution of charge in the bimetallic nanoparticles) and support properties. As for the effect of the alloyed system, the profiles of potential energy obtained by DFT calculations using Pd and PdCo clusters confirmed the beneficial effect of the alloyed nanoparticles 
in boosting the formic acid dehydrogenation reaction. Such profiles were obtained by using a trans- $\mathrm{M}(\mathrm{O})-\mathrm{M}(\mathrm{H}-\mathrm{O})$-bridged configuration ( $\mathrm{M}=\mathrm{Pd}$ or $\mathrm{Co}$ ) as starting point (specie designed as I). The reaction steps were determined to be as follows:Step 1: O-H bond cleavage and formation of $\mathrm{HCOO}^{-}$(II) via transition state $\mathrm{TS}_{\mathrm{I} / \mathrm{II}}$;-Step 2: isomerization to a trans- $\mathrm{M}(\mathrm{H})$ $\mathrm{Pd}(\mathrm{O})$-bridged $\mathrm{HCOOH}$ configuration (III) via transition state $\mathrm{TS}_{\mathrm{II} / \mathrm{III}}$;-Step 3: C-H bond dissociation leading to Pd-H species (IV) and $\mathrm{CO}_{2}$ via the transition state TS III/IV;-Step 4: $\mathrm{H}_{2}$ release via $\mathrm{TS}_{\mathrm{IV} / \mathrm{V}}$. The profiles of potential energy and energy barriers for each reaction step calculated for monometallic and alloyed catalysts are depicted in Figure 11. The energy barriers for Steps 1-4 were calculated to be $44.7,14.2,27.8$, and 80.3 kcal mol ${ }^{-1}$, respectively, for the monometallic $\mathrm{Pd}_{43}$ cluster and $31.3,12.25,14.5$, and $65.4 \mathrm{kcal} \mathrm{mol}^{-1}$, respectively, for the $\mathrm{Pd}_{22} \mathrm{Co}_{21}$ cluster. According to those values, a reduction in the energy barriers in all reaction steps was observed in the presence of the bimetallic system as compared to the monometallic catalyst, being particularly important for the energy barrier of step 3 (C-H bond dissociation), in which a reduction of $48 \%$ of the energy barrier calculated for the Pd catalyst was achieved by the bimetallic catalyst. Then, from that result, the positive role of the bimetallic PdCo system in boosting the C$\mathrm{H}$ bond cleavage was pointed out. In addition, the role of the bimetallic system in catalyzing the formic acid dehydrogenation reaction, particularly in assisting the $\mathrm{C}-\mathrm{H}$ bond dissociation, was confirmed by KIE experiments using $\mathrm{HCOOH}$, HCOOD, and $\mathrm{DCOOH}$.

Then, from all the experimental and theoretical results encompassed in that investigation, it was concluded that the resulting $\mathrm{PdCo} / \mathrm{g}-\mathrm{C}_{3} \mathrm{~N}_{4}$ catalytic system under study was a good alternative to the traditionally more widely investigated catalysts based on PdAg or PdAu nanoparticles. The selection of an adequate support was crucial to developing small and well-distributed alloyed nanoparticles. Furthermore, it was observed that the composition of the nanoparticles (Pd/Co molar ratio) was a key aspect to control the size of the nanoparticles, as well as the existence of electron
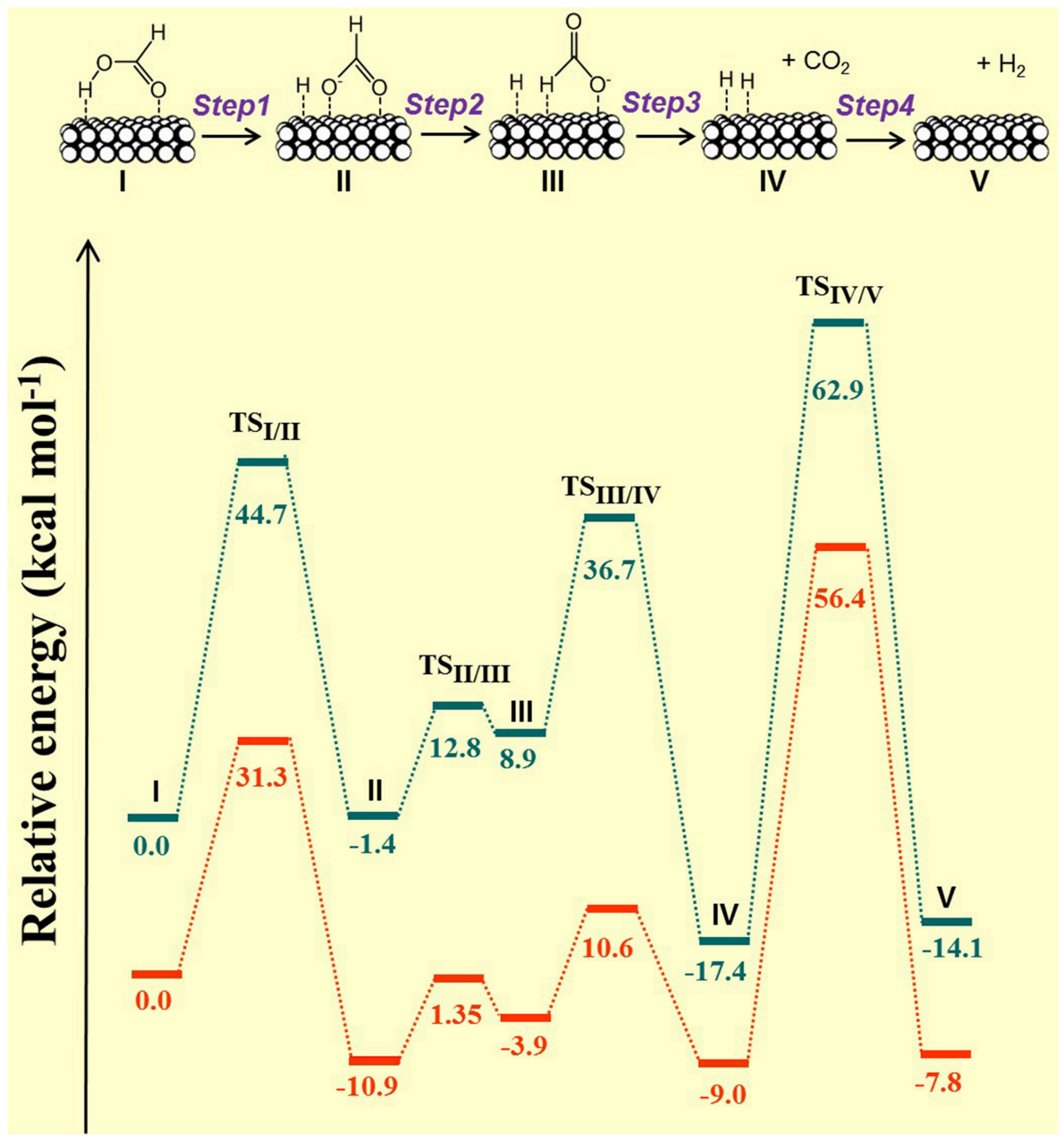

FIGURE 11 | Reaction pathway and profiles of potential energy for the formic acid dehydrogenation reaction catalyzed by $\mathrm{Pd}$ monometallic (Pd 43 , in blue) and bimetallic $\left(\mathrm{Pd}_{22} \mathrm{Co}_{21}\right.$, in orange) clusters. Adapted with permission from Navlani-García et al. (2018b). Copyright 2018 Elsevier. 
rich Pd species. The combination of all these features, together with the basicity of the support used, could afford the preparation of efficient and selective catalysts for the formic acid dehydrogenation reaction, achieving a TOF value of $1,193 \mathrm{~h}^{-1}$ [for the best-performing catalyst among investigated; $\left.\mathrm{PdCo} / \mathrm{g}-\mathrm{C}_{3} \mathrm{~N}_{4}(1 / 0.7)\right]$ and suppressing the production of undesired $\mathrm{CO}(<5 \mathrm{ppm})$. It should be mentioned that such a TOF value is higher than some other g- $\mathrm{C}_{3} \mathrm{~N}_{4}$-based catalysts previously reported in the literature, such as $\mathrm{Ag}_{9} \mathrm{Pd}_{91} / g-\mathrm{C}_{3} \mathrm{~N}_{4}$ (TOF of $480 \mathrm{~h}^{-1}$ at $50^{\circ} \mathrm{C}$ ) (Yao et al., 2017), $\mathrm{Pd} / 1.0 \mathrm{Ti}-\mathrm{g}-\mathrm{C}_{3} \mathrm{~N}_{4}$ (TOF of $77 \mathrm{~h}^{-1}$ at $30^{\circ} \mathrm{C}$ ) (Wu et al., 2017), or $\mathrm{Pd} / \mathrm{mpg}-\mathrm{C}_{3} \mathrm{~N}_{4}$ (TOF of $144 \mathrm{~h}^{-1}$ at $25^{\circ} \mathrm{C}$ ) (Lee et al., 2014).

\section{CONCLUSIONS AND OUTLOOK}

In the present review, some of the investigations recently conducted in our research group tackling the design of efficient catalysts for the production of hydrogen via dehydrogenation of formic acid are summarized. Firstly, in order to contextualize the importance of a such investigation, a brief description of the role of hydrogen in the future energy scenario was highlighted by pointing out the urgency of finding alternatives to fossil fuels, which are currently used as the main source to obtain energy. The importance of chemical hydrogen storage in overcoming the safety drawbacks of physical hydrogen storage was mentioned, and the superiority of formic acid over other hydrogen carrier molecules was justified in the introduction section of the present manuscript. After that, some of our representative investigations on heterogeneous carbon-supported palladium catalysts for the formic acid dehydrogenation reaction in liquid-phase were summarized. In the selected studies herein described, important features of both metal active phase and catalytic supports were investigated in order to find the optimum catalysts under the experimental conditions used in each case. The first study was based on the investigation of the size sensitivity over carbonsupported palladium nanoparticles with sizes ranging from 2.7 to $5.5 \mathrm{~nm}$, from which an optimum average nanoparticle size of $3.9 \mathrm{~nm}$ was found under the experimental conditions used in that case. The next step in our investigation was aimed at the optimization of the composition of carbon-supported PdAg catalysts by means of identifying the best-performing $\mathrm{Pd} / \mathrm{Ag}$ ratio and modulating the surface composition of the nanoparticles by using the assistance of PVP as a capping agent. After that, our study on Pd catalysts supported on nitrogendoped carbon xerogels was included to highlight the role of the nitrogen functional groups present in carbon materials to achieve efficient catalysis for the studied application. It was found that, aside from the functionalization of the support, its porous structure played a key role in the final catalytic performances. Finally, in an attempt to develop cost-effective materials for this application, PdCo alloyed catalysts were investigated by optimizing the composition of the nanoparticles while using graphitic carbon nitride as the catalytic support. In that case, properties of both metal nanoparticles (size, composition, and presence of electron-rich Pd species) and support (nitrogen functionalities and ability to afford small and well-distributed nanoparticles) were responsible for the efficient performance of the catalysts. All the studies herein summarized exemplified the importance of some of the most representative parameters to be controlled in order to achieve efficient catalysts for the formic acid dehydrogenation reaction.

From our results and those found in the ample literature reporting on the design and preparation of heterogeneous catalysts for the formic acid dehydrogenation reaction, it can be understood that, even though great breakthroughs have recently been achieved in the last years, there is still the possibility for further improvements. It could be envisaged that the stability of the catalysts will be the main issue to be improved in future investigations since this aspect is lacking in most of the systems reported so far, and it is a crucial feature for the practical application of the catalysts. In this respect, modulating the nanoparticle-support interactions could be of great importance in achieving durable catalysts, and the incorporation of an adequate heteroatom doping level in the carbon material structure might be a promising tool. Furthermore, the use of some other carbon materials apart from the most widely investigated activated carbons might help in finding interesting catalytic systems for the present application upon suitable surface functionalization. Optimizing the synthetic procedure so that the porosity of the carbon material support can be fully utilized in anchoring and dispersing the metallic active phase might be another point of interest to achieve active and durable catalysts, and finding a suitable capping agent able to prevent the nanoparticle sintering under reaction conditions while preserving their composition could be envisaged as a promising approach. As for the composition of the metallic active phase, the use of non-noble metal-containing nanoparticles could be expected to be investigated more often in the coming years to find cost-efficient yet active catalysts in formic acid dehydrogenation reaction.

\section{AUTHOR CONTRIBUTIONS}

MN-G designed and performed the experiments corresponding to the publications reviewed in the present manuscript, analyzed the results and conceived and wrote the manuscript, KM contributed to the conception of the study and helped with the discussion of the results, DS-T helped with the design and development of the catalysts and contributed to the manuscript writing and revision, $\mathrm{YK}$ and $\mathrm{HY}$ oversaw the study. All authors approved the manuscript for publication.

\section{ACKNOWLEDGMENTS}

We are thankful for the financial support from JST and PRESTO (JPMJPR1544) as well as for Grants-in-Aid for Scientific Research (Nos. 26220911, 25289289, and 26630409, 26620194) from the Japan Society for the Promotion of Science (JSPS) and MEXT and the Elemental Strategy Initiative to Form Core Research Center MN-G (A17F173810) and DS-T (J171015004) thank JSPS for the International Postdoctoral Research Fellowships. 


\section{REFERENCES}

Afif, A., Radenahmad, N., Cheok, Q., Shams, S., Kim, J. H., and Azad, A. K. (2016). Ammonia-fed fuel cells: a comprehensive review. Renew. Sustain. Energy Rev. 60, 822-835. doi: 10.1016/j.rser.2016.01.120

Bagreev, A., Menendez, J. A., Dukhno, I., Tarasenko, Y., and Bandosz, T. J. (2004). Bituminous coal-based activated carbons modified with nitrogen as adsorbents of hydrogen sulfide. Carbon 42, 469-476. doi: 10.1016/j.carbon.2003.10.042

Bashkova, S., Bagreev, A., and Bandosz, T. J. (2003). Adsorption/oxidation of $\mathrm{CH}_{3} \mathrm{SH}$ on activated carbons containing nitrogen. Langmuir 19, 6115-6121. doi: $10.1021 / \mathrm{la} 0300030$

Bavykina, A. V., Goesten, M. G., Kapteijn, F., Makkee, M., and Gascon, J. (2015). Efficient production of hydrogen from formic acid using a Covalent Triazine Framework supported molecular catalyst. ChemSusChem 8, 809-812. doi: $10.1002 /$ cssc. 201403173

Bhowmik, T., Kundu, M. K., and Barman, S. (2015). Ultra small gold nanoparticlesgraphitic carbon nitride composite: an efficient catalyst for ultrafast reduction of 4-nitrophenol and removal of organic dyes from water. RSC Adv. 5, 38760-38773. doi: 10.1039/C5RA04913J

Bi, Q. Y., Lin, J. D., Liu, Y. M., He, H. Y., Huang, F. Q., and Cao, Y. (2016). Dehydrogenation of formic acid at room temperature: boosting palladium nanoparticle efficiency by coupling with pyridinic-nitrogen-doped carbon. Angew. Chem. Int. Ed. 55, 11849-11853. doi: 10.1002/anie.2016 05961

Boddien, A., Loges, B., Gärtner, F., Torborg, C., Fumino, K., Junge, H., et al. (2010). Iron-catalyzed hydrogen production from formic acid. J. Am. Chem. Soc. 132, 8924-8934. doi: 10.1021/ja100925n

Boddien, A., Loges, B., Junge, H., Gärtner, F., Noyes, J. R., and Beller, M. (2009). Continuous hydrogen generation from formic acid. Adv. Synth. Catal. 351, 2517-2520. doi: 10.1002/adsc.200900431

Bulushev, D. A., Zacharska, M., Lisitsyn, A. S., Podyacheva, O. Y., Hage, F. S., Ramasse, Q. M., et al. (2016a). Single atoms of Pt-group metals stabilized by Ndoped carbon nanofibers for efficient hydrogen production from formic acid. ACS Catal. 6, 3442-3451. doi: 10.1021/acscatal.6b00476

Bulushev, D. A., Zacharska, M., Shlyakhova, E. V., Chuvilin, A. L., Guo, Y., Beloshapkin, S., et al. (2016b). Single isolated $\mathrm{Pd}^{2+}$ cations supported on $\mathrm{N}$-doped carbon as active sites for hydrogen production from formic acid decomposition. ACS Catal. 6, 681-691. doi: 10.1021/acscatal.5b 02381

Bulut, A., Yurderi, M., Kaya, M., Aydemir, M., Baysal, A., Durap, F., et al. (2018). Amine-functionalized graphene nanosheet-supported PdAuNi alloy nanoparticles: efficient nanocatalyst for formic acid dehydrogenation. New J. Chem. 42, 16103-16114. doi: 10.1039/C8NJ03117G

Cai, Y., Li, X., Zhang, Y., Wei, X., Wang, K., and Chen, J. (2013). Highly efficient dehydrogenation of formic acid over a palladium- angewandte. Angew. Chem. Int. Ed. 52, 1-5. doi: 10.1002/anie.201304652

Cheng, J., Gu, X., Sheng, X., Liu, P., and Su, H. (2016). Exceptional size-dependent catalytic activity enhancement in the room-temperature hydrogen generation from formic acid over bimetallic nanoparticles supported by porous carbon. $J$. Mater. Chem. A 4, 1887-1894. doi: 10.1039/c5ta08534a

Chowdhury, A. D., Agnihotri, N., and De, A. (2015). Hydrolysis of sodium borohydride using Ru-Co-PEDOT nanocomposites as catalyst. Chem. Eng. J. 264, 531-537. doi: 10.1016/j.cej.2014.11.108

Coffey, R. S. (1967). The decomposition of formic acid catalysed by soluble metal complexes. Chem. Commun. 923-924. doi: 10.1039/C1967000923b

Czaun, M., Goeppert, A., Kothandaraman, J., May, R. B., Haiges, R., Prakash, G. K. S., et al. (2014). Formic acid as a hydrogen storage medium: rutheniumcatalyzed generation of hydrogen from formic acid in emulsions. ACS Catal. 4, 311-320. doi: 10.1021/cs4007974

Czaun, M., Kothandaraman, J., Goeppert, A., Yang, B., Greenberg, S., May, R. B., et al. (2016). Iridium-catalyzed continuous hydrogen generation from formic acid and its subsequent utilization in a fuel cell: toward a carbon neutral chemical energy storage. ACS Catal. 6, 7475-7484. doi: 10.1021/acscatal.6b01605

Demirci, U. B. (2015). The hydrogen cycle with the hydrolysis of sodium borohydride: a statistical approach for highlighting the scientific/technical issues to prioritize in the field. Int. J. Hydrogen Energy 40, 2673-2691. doi: 10.1016/j.ijhydene.2014.12.067
Durmaz, T. (2018). The economics of CCS: why have CCS technologies not had an international breakthrough? Renew. Sustain. Energy Rev. 95, 328-340. doi: 10.1016/j.rser.2018.07.007

El-Eskandarany, M. S., Shaban, E., and Alsairafi, A. A. (2016). Synergistic dosing effect of $\mathrm{TiC} / \mathrm{FeCr}$ nanocatalysts on the hydrogenation/dehydrogenation kinetics of nanocrystalline $\mathrm{MgH}_{2}$ powders. Energy 104, 158-170. doi: 10.1016/j.energy.2016.03.104

Enthaler, S., Von Langermann, J., and Schmidt, T. (2010). Carbon dioxide and formic acid - The couple for environmental-friendly hydrogen storage? Energy Environ. Sci. 3, 1207-1217. doi: 10.1039/b907569k

Eppinger, J., and Huang, K.-W. (2017). Formic acid as a hydrogen energy carrier. ACS Energy Lett. 2, 188-195. doi: 10.1021/acsenergylett.6b00574

Fellay, C., Dyson, P. J., and Laurenczy, G. (2008). A viable hydrogen-storage system based on selective formic acid decomposition with a ruthenium catalyst. Angew. Chem. Int. Ed. 47, 3966-3968. doi: 10.1002/anie.200800320

Feng, C., Wang, Y., Gao, S., Shang, N., and Wang, C. (2016). Hydrogen generation at ambient conditions: AgPd bimetal supported on metal-organic framework derived porous carbon as an efficient synergistic catalyst. Catal. Commun. 78, 17-21. doi: 10.1016/j.catcom.2016.01.034

Fukuzumi, S., Kobayashi, T., and Suenobu, T. (2008). Efficient catalytic decomposition of formic acid for the selective generation of $\mathrm{H}_{2}$ and $\mathrm{H} / \mathrm{D}$ exchange with a water-soluble rhodium complex in aqueous solution. ChemSusChem 1, 827-834. doi: 10.1002/cssc.200800147

Fukuzumi, S., Kobayashi, T., and Suenobu, T. (2010). Formic acid acting as an efficient oxygen scavenger in four-electron reduction of oxygen catalyzed by a heterodinuclear iridium-ruthenium complex in water. J. Am. Chem. Soc. 132, 11866-11867. doi: 10.1021/ja104486h

García-Aguilar, J., Navlani-García, M., Berenguer-Murcia, Á., Mori, K., Kuwahara, Y., Yamashita, H., et al. (2016a). Enhanced ammonia-borane decomposition by synergistic catalysis using CoPd nanoparticles supported on titano-silicates. RSC Adv. 6, 91768-91772. doi: 10.1039/C6RA21302B

García-Aguilar, J., Navlani-García, M., Berenguer-Murcia, Á., Mori, K., Kuwahara, Y., Yamashita, H., et al. (2016b). Evolution of the PVP-Pd surface interaction in nanoparticles through the case study of formic acid decomposition. Langmuir 32, 12110-12118. doi: 10.1021/acs.langmuir.6b03149

Graetz, J. (2009). New approaches to hydrogen storage. Chem. Soc. Rev. 38, 73-82. doi: $10.1039 / \mathrm{b} 718842 \mathrm{k}$

Grasemann, M., and Laurenczy, G. (2012). Formic acid as a hydrogen source - recent developments and future trends. Energy Environ. Sci. 5, 8171. doi: 10.1039/c2ee21928j

Gu, X., Lu, Z. H., Jiang, H. L., Akita, T., and Xu, Q. (2011). Synergistic catalysis of metal-organic framework-immobilized Au-Pd nanoparticles in dehydrogenation of formic acid for chemical hydrogen storage. J. Am. Chem. Soc. 133, 11822-11825. doi: 10.1021/ja200122f

Gupta, K., Bersani, M., and Darr, J. A. (2016). Highly efficient electro-reduction of CO2to formic acid by nano-copper. J. Mater. Chem. A 4, 13786-13794. doi: 10.1039/c6ta04874a

He, N., and Li, Z. H. (2016). Palladium-atom catalyzed formic acid decomposition and the switch of reaction mechanism with temperature. Phys. Chem. Chem. Phys. 18, 10005-10017. doi: 10.1039/c6cp00186f

Huang, Y., Xu, J., Ma, X., Huang, Y., Li, Q., and Qiu, H. (2017). An effective low Pd-loading catalyst for hydrogen generation from formic acid. Int. J. Hydrogen Energy 42, 18375-18382. doi: 10.1016/j.ijhydene.2017.04.138

Huang, Y., Zhou, X., Yin, M., Liu, C., and Xing, W. (2010). Novel PdAu@Au/C core-shell catalyst: superior activity and selectivity in formic acid decomposition for hydrogen generation. Chem. Mater. 22, 5122-5128. doi: $10.1021 / \mathrm{cm} 101285 \mathrm{f}$

Hulicova-Jurcakova, D., Seredych, M., Lu, G. Q., and Bandosz, T. J. (2009). Combined effect of nitrogen- and oxygen-containing functional groups of microporous activated carbon on its electrochemical performance in supercapacitors. Adv. Funct. Mater. 19, 438-447. doi: 10.1002/adfm.200801236

Inagaki, M., Tsumura, T., Kinumoto, T., and Toyoda, M. (2019). Graphitic carbon nitrides $\left(\mathrm{g}-\mathrm{C}_{3} \mathrm{~N}_{4}\right)$ with comparative discussion to carbon materials. Carbon 141, 580-607. doi: 10.1016/j.carbon.2018.09.082

Jeon, H.-J., and Chung, Y. M. (2017). Hydrogen production from formic acid dehydrogenation over Pd/C catalysts: effect of metal and support properties on the catalytic performance. Appl. Catal. B Environ. 210, 212-222. doi: 10.1016/j.apcatb.2017.03.070 
Jeon, M., Han, D. J., Lee, K. S., Choi, S. H., Han, J., Nam, S. W., et al. (2016). Electronically modified Pd catalysts supported on N-doped carbon for the dehydrogenation of formic acid. Int. J. Hydrogen Energy 41, 15453-15461. doi: 10.1016/j.ijhydene.2016.04.102

Jiang, K., Xu, K., Zou, S., and Cai, W.-B. (2014). B-doped pd catalyst: boosting room-temperature hydrogen production from formic acid-formate solutions. J. Am. Chem. Soc. 136, 4861-4864. doi: 10.1021/ja5008917

Jiang, M., Wu, H., Li, Z., Ji, D., Li, W., Liu, Y., et al. (2018). Highly selective photoelectrochemical conversion of carbon dioxide to formic acid. ACS Sustain. Chem. Eng. 6, 82-87. doi: 10.1021/acssuschemeng.7b03272

Jiang, Y., Fan, X., Chen, M., Xiao, X., Zhang, Y., Wang, C., et al. (2018). AuPd nanoparticles anchored on nitrogen-decorated carbon nanosheets with highly efficient and selective catalysis for the dehydrogenation of formic acid. J. Phys. Chem. C 122, 4792-4801. doi: 10.1021/acs.jpcc.8b00082

Jin, M. H., Park, J. H., Oh, D., Lee, S. W., Park, J. S., Lee, K. Y., et al. (2018). $\mathrm{Pd} / \mathrm{NH} 2-\mathrm{KIE}-6$ catalysts with exceptional catalytic activity for additive-free formic acid dehydrogenation at room temperature: controlling Pd nanoparticle size by stirring time and types of Pd precursors. Int. J. Hydrogen Energy 43, 1451-1458. doi: 10.1016/j.ijhydene.2017.10.117

Kim, Y., Kim, J., and Kim, D. H. (2018). Investigation on the enhanced catalytic activity of a Ni-promoted Pd/C catalyst for formic acid dehydrogenation: effects of preparation methods and Ni/Pd ratios. RSC Adv. 8, 2441-2448. doi: $10.1039 / \mathrm{c} 7 \mathrm{ra13150j}$

Lan, R., Irvine, J. T. S., and Tao, S. (2012). Ammonia and related chemicals as potential indirect hydrogen storage materials. Int. J. Hydrogen Energy 37, 1482-1494. doi: 10.1016/j.ijhydene.2011.10.004

Lee, D. W., Jin, M. H., Oh, D., Lee, S. W., and Park, J. S. (2017). Straightforward synthesis of hierarchically porous nitrogen-doped carbon via pyrolysis of Chitosan/Urea/KOH mixtures and its application as a support for formic acid dehydrogenation catalysts. ACS Sustain. Chem. Eng. 5, 9935-9944. doi: 10.1021/acssuschemeng.7b01888

Lee, J. H., Ryu, J., Kim, J. Y., Nam, S.-W., Han, J. H., Lim, T.-H., et al. (2014). Carbon dioxide mediated, reversible chemical hydrogen storage using a $\mathrm{Pd}$ nanocatalyst supported on mesoporous graphitic carbon nitride. J. Mater. Chem. A 2, 9490-9495. doi: 10.1039/C4TA01133C

Li, J., Chen, W., Zhao, H., Zheng, X., Wu, L., Pan, H., et al. (2017). Size-dependent catalytic activity over carbon-supported palladium nanoparticles in dehydrogenation of formic acid. J. Catal. 352, 371-381. doi: 10.1016/j.jcat.2017.06.007

Li, S. J., Ping, Y., Yan, J. M., Wang, H. L., Wu, M., and Jiang, Q. (2015). Facile synthesis of AgAuPd/graphene with high performance for hydrogen generation from formic acid. J. Mater. Chem. A 3, 14535-14538. doi: 10.1039/c5ta03111g

Li, Z., Yang, X., Tsumori, N., Liu, Z., Himeda, Y., Autrey, T., et al. (2017). Tandem nitrogen functionalization of porous carbon: toward immobilizing highly active palladium nanoclusters for dehydrogenation of formic acid. ACS Catal. 7, 2720-2724. doi: 10.1021/acscatal.7b00053

Lillo-Ródenas, M. A., Guo, Z. X., Aguey-Zinsou, K. F., Cazorla-Amorós, D., and Linares-Solano, A. (2008). Effects of different carbon materials on $\mathrm{MgH}_{2}$ decomposition. Carbon 46, 126-137. doi: 10.1016/j.carbon.2007.10.033

Liu, H., Liu, X., Yang, W., Shen, M., Geng, S., Yu, C., et al. (2019). Photocatalytic dehydrogenation of formic acid promoted by a superior PdAg@g$\mathrm{C}_{3} \mathrm{~N}_{4}$ Mott-Schottky heterojunction. J. Mater. Chem. A. 7, 2022-2026. doi: 10.1039/C8TA11172C

Liu, J., Lan, L., Li, R., Liu, X., and Wu, C. (2016). Agglomerated Ag-Pd catalyst with performance for hydrogen generation from formic acid at room temperature. Int. J. Hydrogen Energy 41, 951-958. doi: 10.1016/j.ijhydene.2015.10.144

Loges, B., Boddien, A., Junge, H., and Beller, M. (2008). Controlled generation of hydrogen from formic acid amine adducts at room temperature and application in $\mathrm{H}_{2} / \mathrm{O}_{2}$ fuel cells. Angew. Chem. Int. Ed. 47, 3962-3965. doi: 10.1002/anie.200705972

Lu, W., Jia, B., Cui, B., Zhang, Y., Yao, K., Zhao, Y., et al. (2017). Efficient photoelectrochemical reduction of carbon dioxide to formic acid: a functionalized ionic liquid as an absorbent and electrolyte. Angew. Chem. Int. Ed. 56, 11851-11854. doi: 10.1002/anie.201703977

Lu, X., Leung, D. Y. C., Wang, H., Leung, M. K. H., and Xuan, J. (2014). Electrochemical reduction of carbon dioxide to formic acid. ChemElectroChem 1, 836-849. doi: 10.1002/celc.201300206
Masuda, S., Mori, K., Futamura, Y., and Yamashita, H. (2018). PdAg nanoparticles supported on functionalized mesoporous carbon: promotional effect of surface amine groups in reversible hydrogen delivery/storage mediated by formic acid/CO . ACS Catal. 8, 2277-2285. doi: 10.1021/acscatal.7b04099

Matsunami, A., Kuwata, S., and Kayaki, Y. (2017). A bifunctional iridium catalyst modified for persistent hydrogen generation from formic acid: understanding deactivation via cyclometalation of a 1,2-Diphenylethylenediamine motif. ACS Catal. 7, 4479-4484. doi: 10.1021/acscatal.7b01068

Mellmann, D., Sponholz, P., Junge, H., and Beller, M. (2016). Formic acid as a hydrogen storage material-development of homogeneous catalysts for selective hydrogen release. Chem. Soc. Rev. 45, 3954-3988. doi: 10.1039/C5CS00618J

Monney, A., Barsch, E., Sponholz, P., Junge, H., Ludwig, R., and Beller, M. (2014). Base-free hydrogen generation from methanol using a bi-catalytic system. Chem. Commun. 50, 707-709. doi: 10.1039/c3cc47306f

Moret, S., Dyson, P. J., and Laurenczy, G. (2014). Direct synthesis of formic acid from carbon dioxide by hydrogenation in acidic media. Nat. Commun. 5, 1-7. doi: $10.1038 /$ ncomms5017

Mori, K., Dojo, M., and Yamashita, H. (2013). Pd and Pd-Ag nanoparticles within a macroreticular basic resin: an efficient catalyst for hydrogen production from formic acid decomposition. ACS Catal. 3, 1114-1119. doi: 10.1021/cs400148n

Mori, K., Hara, T., Mizugaki, T., Ebitani, K., and Kaneda, K. (2004). Hydroxyapatite-supported palladium nanoclusters: a highly active heterogeneous catalyst for selective oxidation of alcohols by use of molecular oxygen. J. Am. Chem. Soc. 126, 10657-10666. doi: 10.1021/ja0488683

Mori, K., Kakudo, H., and Yamashita, H. (2014). Creation of nickel-based active species within a macroreticular acidic resin: a noble-metal-free heterogeneous catalyst for visible-light-driven H2evolution from water. ACS Catal. 4, 4129-4135. doi: 10.1021/cs501119d

Mori, K., Masuda, S., Tanaka, H., Yoshizawa, K., Che, M., and Yamashita, H. (2017a). Phenylamine-functionalized mesoporous silica supported PdAg nanoparticles: a dual heterogeneous catalyst for formic acid/ $\mathrm{CO}_{2}$-mediated chemical hydrogen delivery/storage. Chem. Commun. 53, 4677-4680. doi: $10.1039 / \mathrm{c} 7 \mathrm{cc} 00864 \mathrm{c}$

Mori, K., Naka, K., Masuda, S., Miyawaki, K., and Yamashita, H. (2017b). Palladium copper chromium ternary nanoparticles constructed in situ within a basic resin: enhanced activity in the dehydrogenation of formic acid. ChemCatChem 9, 3456-3462. doi: 10.1002/cctc.201700595

Mori, K., Sano, T., Kobayashi, H., and Yamashita, H. (2018). Surface engineering of a supported PdAg catalyst for hydrogenation of $\mathrm{CO}_{2}$ to formic acid: elucidating the active Pd atoms in alloy nanoparticles. J. Am. Chem. Soc. 140, 8902-8909. doi: 10.1021/jacs.8b04852

Mori, K., Tanaka, H., Dojo, M., Yoshizawa, K., and Yamashita, H. (2015). Synergic catalysis of $\mathrm{PdCu}$ alloy nanoparticles within a macroreticular basic resin for hydrogen production from formic acid. Chem. A Eur. J. 21, 12085-12092. doi: $10.1002 /$ chem. 201501760

Nabid, M. R., Bide, Y., and Etemadi, B. (2017). Ag@Pd nanoparticles immobilized on a nitrogen-doped graphene carbon nanotube aerogel as a superb catalyst for the dehydrogenation of formic acid. New J. Chem. 41, 10773-10779. doi: 10.1039/C7NJ01108C

Navlani-García, M., Martis, M., Lozano-Castelló, D., Cazorla-Amorós, D., Mori, K., and Yamashita, H. (2015a). Investigation of Pd nanoparticles supported on zeolites for hydrogen production from formic acid dehydrogenation. Catal. Sci. Technol. 5, 364-371. doi: 10.1039/c4cy00667d

Navlani-García, M., Mori, K., Kuwahara, Y., and Yamashita, H. (2018a). Recent strategies targeting efficient hydrogen production from chemical hydrogen storage materials over carbon-supported catalysts. NPG Asia Mater. 10, 277-292. doi: 10.1038/s41427-018-0025-6

Navlani-García, M., Mori, K., Nozaki, A., Kuwahara, Y., and Yamashita, H. (2016a). Highly efficient $\mathrm{Ru}$ /carbon catalysts prepared by pyrolysis of supported $\mathrm{Ru}$ complex towards the hydrogen production from ammonia borane. Appl. Catal. A Gen. 527, 45-52. doi: 10.1016/j.apcata.2016.08.018

Navlani-García, M., Mori, K., Nozaki, A., Kuwahara, Y., and Yamashita, H. (2016b). Investigation of size sensitivity in the hydrogen production from formic acid over carbon-supported Pd nanoparticles. Chem. Select 1, 1879-1886. doi: 10.1002/slct.201600559

Navlani-García, M., Mori, K., Nozaki, A., Kuwahara, Y., and Yamashita, H. (2016c). Screening of carbon-supported PdAg nanoparticles in the 
hydrogen production from formic acid. Ind. Eng. Chem. Res. 55, 7612-7620. doi: 10.1021/acs.iecr.6b01635

Navlani-García, M., Mori, K., Wen, M., Kuwahara, Y., and Yamshita, H. (2015b). Size effect of carbon-supported pd nanoparticles in the hydrogen production from formic acid. Bull. Chem. Soc. Jpn. 1370, 78-80. doi: 10.1080/03758397.1955.10857269

Navlani-García, M., Salinas-Torres, D., Mori, K., Kuwahara, Y., and Yamashita, H. (2018b). Enhanced formic acid dehydrogenation by the synergistic alloying effect of PdCo catalysts supported on graphitic carbon nitride. Int. J. Hydrogen Energy. doi: 10.1016/j.ijhydene.2018.11.057. [Epub ahead of print].

Navlani-García, M., Salinas-Torres, D., Mori, K., Léonard, A. F., Kuwahara, Y., Job, N., et al. (2019). Insights on palladium decorated nitrogen-doped carbon xerogels for the hydrogen production from formic acid. Catal. Today 324, 90-96. doi: 10.1016/j.cattod.2018.06.013

Navlani-garcía, M., Verma, P., Kuwahara, Y., and Kamegawa, T. (2018). Visible-light-enhanced catalytic activity of $\mathrm{Ru}$ nanoparticles over carbon modified g- $\mathrm{C}_{3} \mathrm{~N}_{4}$. J. Photochem. Photobiol. A 358, 327-333. doi: 10.1016/j.jphotochem.2017.09.007

Nguyen, K. H., and Kakinaka, M. (2018). Renewable energy consumption, carbon emissions, and development stages: some evidence from panel cointegration analysis. Renew. Energy 132, 1049-1057. doi: 10.1016/j.renene.2018.08.069

Nielsen, M., Alberico, E., Baumann, W., Drexler, H. J., Junge, H., Gladiali, S., et al. (2013). Low-temperature aqueous-phase methanol dehydrogenation to hydrogen and carbon dioxide. Nature 495, 85-89. doi: 10.1038/nature11891

Oh, T. H. (2016). A formic acid hydrogen generator using $\mathrm{Pd} / \mathrm{C}_{3} \mathrm{~N}_{4}$ catalyst for mobile proton exchange membrane fuel cell systems. Energy 112, 679-685. doi: 10.1016/j.energy.2016.06.096

Paul, R., Reifenberger, R. G., Fisher, T. S., and Zemlyanov, D. Y. (2015). Atomic layer deposition of $\mathrm{FeO}$ on $\mathrm{Pt}(111)$ by ferrocene adsorption and oxidation. Chem. Mater. 27, 5915-5924. doi: 10.1021/acs.chemmater.5b01778

Ping, Y., Yan, J. M., Wang, Z. L., Wang, H. L., and Jiang, Q. (2013). $\mathrm{Ag}_{0.1}-\mathrm{Pd}_{0.9} / \mathrm{rGO}$ : An efficient catalyst for hydrogen generation from formic acid/sodium formate. J. Mater. Chem. A 1, 12188-12191. doi: $10.1039 / \mathrm{c} 3 \operatorname{ta} 12724 \mathrm{a}$

Podyacheva, O. Y., Bulushev, D. A., Suboch, A. N., Svintsitskiy, D. A., Lisitsyn, A. S., Modin, E., et al. (2018). Highly stable single-atom catalyst with ionic $\mathrm{Pd}$ active sites supported on $\mathrm{N}$-doped carbon nanotubes for formic acid decomposition. ChemSusChem 11, 3724-3727. doi: 10.1002/cssc.201801679

Premkumar, J., and Ramaraj, R. (1997). Photocatalytic reduction of carbon dioxide to formic acid at porphyrin and phthalocyanine adsorbed Nafion membranes. J. Photochem. Photobiol. A Chem. 110, 53-58. doi: 10.1016/S1010-6030(97)00156-1

Qin, G., Zhang, Y., Ke, X., Tong, X., Sun, Z., Liang, M., et al. (2013). Photocatalytic reduction of carbon dioxide to formic acid, formaldehyde, and methanol using dye-sensitized $\mathrm{TiO}_{2}$ film. Appl. Catal. B Environ. 129, 59-605. doi: 10.1016/j.apcatb.2012.10.012

Qin, Y., Wang, J., Wu, Y., and Wang, L. (2014). Improved hydrogen production from formic acid under ambient conditions using a PdAu catalyst on a graphene nanosheets-carbon black support. RSC Adv. 4, 30068-30073. doi: $10.1039 / \mathrm{C} 4 \mathrm{RA} 05379 \mathrm{~F}$

Qin, Y.-L., Wang, J., Meng, F.-Z., Wang, L.-M., and Zhang, X.-B. (2013). Efficient PdNi and PdNi@Pd-catalyzed hydrogen generation via formic acid decomposition at room temperature. Chem. Commun. 49, 10028-10030. doi: $10.1039 / \mathrm{c} 3 \mathrm{cc} 46248 \mathrm{j}$

Reddy, G. K., and Smirniotis, P. G. (2015). Water Gas Shift Reaction: Research Developments and Applications. Elsevier. doi: 10.1016/C2013-0-09821-0

Rodríguez-Reinoso, F. (2010). The role of carbon materials in heterogeneous catalysis. Nonlin. Anal. Theory, Methods Appl. 72, 2658-2683. doi: 10.1016/j.na.2009.11.013

Rosen, M. A., and Koohi-Fayegh, S. (2016). The prospects for hydrogen as an energy carrier: an overview of hydrogen energy and hydrogen energy systems. Energy, Ecol. Environ. 1, 10-29. doi: 10.1007/s40974-016-0005-z

Salinas-Torres, D., Léonard, A. F., Stergiopoulos, V., Busby, Y., Pireaux, J. J., and Job, N. (2018). Effect of nitrogen doping on the pore texture of carbon xerogels based on resorcinol-melamine-formaldehyde precursors. Microporous Mesoporous Mater. 256, 190-198. doi: 10.1016/j.micromeso.2017.08.004

Sanchez, F., Alotaibi, M. H., Motta, D., Chan-Thaw, C. E., Rakotomahevitra, A., Tabanelli, T., et al. (2018). Hydrogen production from formic acid decomposition in the liquid phase using Pd nanoparticles supported on CNFs with different surface properties. Sustain. Energy Fuels 2, 2705-2716. doi: $10.1039 / \mathrm{c} 8 \mathrm{se} 00338 \mathrm{f}$

Song, F. Z., Zhu, Q. L., Yang, X., Zhan, W. W., Pachfule, P., Tsumori, N., et al. (2018). Metal-organic framework templated porous carbon-metal oxide/reduced graphene oxide as superior support of bimetallic nanoparticles for efficient hydrogen generation from formic acid. Adv. Energy Mater. 8, 1-5. doi: 10.1002/aenm.201701416

Strauss, S., Whitmire, K., and Shriver, D. (1979). Rhodium (I) catalyzed decomposition of formic acid. J. Organomet. Chem. 174, C59-C62. doi: $10.1016 / \mathrm{S} 0022-328 \mathrm{X}(00) 85605-3$

Sun, J., Qiu, H., Cao, W., Fu, H., Wan, H., Xu, Z., et al. (2019). Ultrafine $\mathrm{Pd}$ particles embedded in nitrogen-enriched mesoporous carbon for efficient $\mathrm{H}_{2}$ production from formic acid decomposition. ACS Sustain. Chem. Eng. 7, 1963-1972. doi: 10.1021/acssuschemeng.8b04130

Tedsree, K., Li, T., Jones, S., Chan, C. W. A., Yu, K. M. K., Bagot, P. A. J., et al. (2011). Hydrogen production from formic acid decomposition at room temperature using a Ag-Pd core-shell nanocatalyst. Nat. Nanotechnol. 6, 302-307. doi: 10.1038/nnano.2011.42

Wang, X., Qi, G.-W., Tan, C.-H., Li, Y.-P., Guo, J., Pang, X.-J., et al. (2014). $\mathrm{Pd} / \mathrm{C}$ nanocatalyst with high turnover frequency for hydrogen generation from the formic acid-formate mixtures. Int. J. Hydrogen Energy 39, 837-843. doi: 10.1016/j.ijhydene.2013.10.154

Wang, Y., Wang, X., and Antonietti, M. (2012). Polymeric graphitic carbon nitride as a heterogeneous organocatalyst: from photochemistry to multipurpose catalysis to sustainable chemistry. Angew. Chem. Int. Ed. 51, 68-89. doi: 10.1002/anie.201101182

Wang, Z.-L., Ping, Y., Yan, J. M., Wang, H. L., and Jiang, Q. (2014b). Hydrogen generation from formic acid decomposition at room temperature using a NiAuPd alloy nanocatalyst. Int. J. Hydrogen Energy 39, 4850-4856. doi: 10.1016/j.ijhydene.2013.12.148

Wang, Z.-L., Yan, J.-M., Wang, H.-L., Ping, Y., and Jiang, Q. (2012). Pd/C synthesized with citric acid: an efficient catalyst for hydrogen generation from formic acid/sodium formate. Sci. Rep. 2:598. doi: 10.1038/srep00598

Wang, Z.-L., Yan, J.-M., Zhang, Y.-F., Ping, Y., Wang, H.-L., and Jiang, Q. (2014a). Facile synthesis of nitrogen-doped graphene supported $\mathrm{AuPd}-\mathrm{CeO}_{2}$ nanocomposites with high-performance for hydrogen generation from formic acid at room temperature. Nanoscale 6, 3073-3077. doi: 10.1039/C3NR05809C

Wang, Z.-L., Yan, J. M., Ping, Y., Wang, H. L., Zheng, W. T., and Jiang, Q. (2013a). An efficient CoAuPd/C catalyst for hydrogen generation from formic acid at room temperature. Angew. Chem. Int. Ed. 52, 4406-4409. doi: 10.1002/anie.201301009

Wang, Z. L., Yan, J. M., Wang, H. L., Ping, Y., and Jiang, Q. (2013b). Au@Pd coreshell nanoclusters growing on nitrogen-doped mildly reduced graphene oxide with enhanced catalytic performance for hydrogen generation from formic acid. J. Mater. Chem. A 1, 12721-12725. doi: 10.1039/c3ta12531a

Wen, M., Mori, K., Kuwahara, Y., and Yamashita, H. (2017). Plasmonic $\mathrm{Au} @ \mathrm{Pd}$ nanoparticles supported on a basic metal-organic framework: synergic boosting of $\mathrm{H}_{2}$ production from formic acid. ACS Energy Lett. 2, 1-7. doi: 10.1021/acsenergylett.6b00558

Williams, R., Crandall, R. S., and Bloom, A. (1978). Use of carbon dioxide in energy storage. Appl. Phys. Lett. 33, 381-383. doi: 10.1063/1.90403

Wu, S., Yang, F., Sun, P., and Chen, T. (2014). Au-Pd alloy catalyst with high performance for hydrogen generation from formic acid-formate solution at nearly $0{ }^{\circ} \mathrm{C}$. RSC $A d v .4,44500-44503$. doi: 10.1039/C4RA08389J

Wu, S., Yang, F., Wang, H., Chen, R., Sun, P., and Chen, T. (2015). $\mathrm{Mg}^{2+}$ assisted low temperature reduction of alloyed AuPd/C: an efficient catalyst for hydrogen generation from formic acid at room temperature. Chem. Commun. 51, 10887-10890. doi: 10.1039/C5CC02604K

Wu, Y., Wen, M., Navlani-García, M., Kuwahara, Y., Mori, K., and Yamashita, H. (2017). Palladium nanoparticles supported on titanium doped graphitic carbon nitride for formic acid dehydrogenation. Chem. Asian J. 12, 860-867. doi: 10.1002/asia.201700041

Xie, W., and Schlücker, S. (2018). Surface-enhanced Raman spectroscopic detection of molecular chemo- and plasmo-catalysis on noble metal nanoparticles. Chem. Commun. 54, 2326-2336. doi: 10.1039/c7cc07951f

Yan, J.-M., Wang, Z.-L., Gu, L., Li, S.-J., Wang, H.-L., Zheng, W.-T., et al. (2015). AuPd-MnO x /MOF-Graphene: an efficient catalyst for hydrogen 
production from formic acid at room temperature. Adv. Energy Mater. 5:1500107. doi: 10.1002/aenm.201500107

Yan, J. M., Li, S. J., Yi, S. S., Wulan, B. R., Zheng, W. T., and Jiang, Q. (2018). Anchoring and upgrading ultrafine NiPd on room-temperaturesynthesized bifunctional $\mathrm{NH}_{2}-\mathrm{N}$-rGO toward low-cost and highly efficient catalysts for selective formic acid dehydrogenation. Adv. Mater. 30, 2-9. doi: 10.1002/adma.201703038

Yang, L., Hua, X., Su, J., Luo, W., Chen, S., and Cheng, G. (2015). Highly efficient hydrogen generation from formic acid-sodium formate over monodisperse AgPd nanoparticles at room temperature. Appl. Catal. B Environ. 168-169, 423-428. doi: 10.1016/j.apcatb.2015.01.003

Yang, L., Luo, W., and Cheng, G. (2016). Monodisperse CoAgPd nanoparticles assembled on graphene for efficient hydrogen generation from formic acid at room temperature. Int. J. Hydrogen Energy 41, 439-446. doi: 10.1016/j.ijhydene.2015.10.074

Yao, F., Li, X., Wan, C., Xu, L., An, Y., Ye, M., et al. (2017). Highly efficient hydrogen release from formic acid using a graphitic carbon nitride-supported AgPd nanoparticle catalyst. Appl. Surf. Sci. 426, 605-611. doi: 10.1016/j.apsusc.2017.07.193

Yoo, J. S., Abild-Pedersen, F., Nørskov, J. K., and Studt, F. (2014). Theoretical analysis of transition-metal catalysts for formic acid decomposition. ACS Catal. 4, 1226-1233. doi: 10.1021/cs400664z

Zell, T., Butschke, B., Ben-David, Y., and Milstein, D. (2013). Efficient hydrogen liberation from formic acid catalyzed by a well-defined iron pincer complex under mild conditions. Chem. Eur. J. 19, 8068-8072. doi: $10.1002 /$ chem. 201301383

Zhang, S., Jiang, B., Jiang, K., and Cai, W., Bin (2017). Surfactant-free synthesis of carbon-supported palladium nanoparticles and size-dependent hydrogen production from formic acid-formate solution. ACS Appl. Mater. Interfaces 9, 24678-24687. doi: 10.1021/acsami.7b08441

Zhang, S., Metin, Ö., Su, D., and Sun, S. (2013). Monodisperse AgPd alloy nanoparticles and their superior catalysis for the dehydrogenation of formic acid. Angew. Chem. Int. Ed. 52, 3681-3684. doi: 10.1002/anie.201300276

Zhang, X., Shang, N., Shang, H., Du, T., Zhou, X., Feng, C., et al. (2019). Nitrogen-decorated porous carbon supported AgPd nanoparticles for boosting hydrogen generation from formic acid. Energy Technol. 7, 140-145. doi: 10.1002/ente.201800522

Zhang, X., Shang, N., Zhou, X., Feng, C., Gao, S., Wu, Q., et al. (2017a). $\mathrm{AgPd}-\mathrm{MnO}_{\mathrm{x}}$ supported on carbon nanospheres: an efficient catalyst for dehydrogenation of formic acid. New J. Chem. 41, 3443-3449. doi: 10.1039/c6nj03873e
Zhang, X., Zhao, Y., Hu, S., Gliege, M. E., Liu, Y., Liu, R., et al. (2017b). Electrochemical reduction of carbon dioxide to formic acid in ionic liquid $[\mathrm{Emim}]\left[\mathrm{N}(\mathrm{CN})_{2}\right] /$ water system. Electrochim. Acta 247, 281-287. doi: 10.1016/j.electacta.2017.06.112

Zhong, H., Iguchi, M., Chatterjee, M., Himeda, Y., Xu, Q., and Kawanami, H. (2018). Formic acid-based liquid organic hydrogen carrier system with heterogeneous catalysts. Adv. Sustain. Syst. 2:1700161. doi: 10.1002/adsu.201700161

Zhou, J. P., Zhang, J., Dai, X. H., Wang, X., and Zhang, S. Y. (2016). Formic acid-ammonium formate mixture: a new system with extremely high dehydrogenation activity and capacity. Int. J. Hydrogen Energy 41, 22059-22066. doi: 10.1016/j.ijhydene.2016.10.015

Zhou, X., Huang, Y., Liu, C., Liao, J., Lu, T., and Xing, W. (2010). Available hydrogen from formic acid decomposed by rare earth elements promoted Pd-Au/C catalysts at low temperature. ChemSusChem 3, 1379-1382. doi: 10.1002/cssc.201000199

Zhu, J., Xiao, P., Li, H., and Carabineiro, A. C. (2014). Graphitic carbon nitride: synthesis, properties, and applications in catalysis. ACS Appl. Mater. Interfaces 6, 16449-16465. doi: 10.1021/am502925j

Zhu, Q. L., Tsumori, N., and Xu, Q. (2014). Sodium hydroxide-assisted growth of uniform Pd nanoparticles on nanoporous carbon MSC-30 for efficient and complete dehydrogenation of formic acid under ambient conditions. Chem. Sci. 5, 195-199. doi: 10.1039/c3sc52448e

Zhu, Q. L., Tsumori, N., and Xu, Q. (2015). Immobilizing extremely catalytically active palladium nanoparticles to carbon nanospheres: a weakly-capping growth approach. J. Am. Chem. Soc. 137, 11743-11748. doi: 10.1021/jacs.5b06707

Zhu, Q. L., and Xu, Q. (2015). Liquid organic and inorganic chemical hydrides for high-capacity hydrogen storage. 8, 478-512. doi: 10.1039/c4ee03690e

Conflict of Interest Statement: The authors declare that the research was conducted in the absence of any commercial or financial relationships that could be construed as a potential conflict of interest.

Copyright (c) 2019 Navlani-García, Mori, Salinas-Torres, Kuwahara and Yamashita. This is an open-access article distributed under the terms of the Creative Commons Attribution License (CC BY). The use, distribution or reproduction in other forums is permitted, provided the original author(s) and the copyright owner(s) are credited and that the original publication in this journal is cited, in accordance with accepted academic practice. No use, distribution or reproduction is permitted which does not comply with these terms. 